\title{
Diagnosing type 2 diabetes using Hemoglobin A1c: a systematic review and meta-analysis of the diagnostic cutpoint based on microvascular complications
}

\author{
Alexandra E. Butler ${ }^{1}$ (1) $\cdot$ Emma English $^{2} \cdot$ Eric S. Kilpatrick $^{3} \cdot$ Linda Östlundh $^{4} \cdot$ Hiam S. Chemaitelly $^{5}$. \\ Laith J. Abu-Raddad ${ }^{5} \cdot$ K. George M. M. Alberti ${ }^{6} \cdot$ Stephen L. Atkin ${ }^{7} \cdot$ W. Garry John ${ }^{2,8}$
}

Received: 20 August 2020 / Accepted: 11 September 2020 / Published online: 3 November 2020

(c) The Author(s) 2020

\begin{abstract}
Aims Diabetic microvascular complications of retinopathy, nephropathy and neuropathy may occur at hemoglobin A1c levels $(\mathrm{HbAlc}$ ) below the $6.5 \%$ ( $48 \mathrm{mmol} / \mathrm{mol}$ ) diagnostic threshold. Our objective was to assess the validity of the $\mathrm{HbA} 1 \mathrm{c}$ diagnostic cutpoint of $6.5 \%$ based upon published evidence of the prevalence of retinopathy, nephropathy and neuropathy as markers of diabetes.

Methods Data Sources PubMed, Embase, Cochrane, Scopus and CINAHL from 1990-March 2019, grey literature sources. Study Selection All studies reported after 1990 (to ensure standardized HbA1c values) where HbA1c levels were presented in relation to prevalence of retinopathy, nephropathy or neuropathy in subjects not known to have diabetes. Data Extraction Studies were screened independently, data abstracted, and risk of bias appraised. Data Synthesis Data were synthesized using $\mathrm{HbAlc}$ categories of $<6.0 \%$ ( $<42 \mathrm{mmol} / \mathrm{mol}), 6.0-6.4 \%(42-47 \mathrm{mmol} / \mathrm{mol})$ and $\geq 6.5 \%$ ( $\geq 48 \mathrm{mmol} / \mathrm{mol})$. Random-effects meta-analyses were conducted for retinopathy, nephropathy and neuropathy prevalence stratified by HbA1c categories. Random-effects multivariable meta-regression was conducted to identify predictors of retinopathy prevalence and sources of between-study heterogeneity.

Results Pooled mean prevalence was: 4.0\%(95\% CI: 3.2-5.0\%) for retinopathy, 10.5\% (95\% CI: 4.0-19.5\%) for nephropathy, 2.5\% (95\% CI: $1.1-4.3 \%$ ) for neuropathy. Mean prevalence when stratified for $\mathrm{HbA} 1 \mathrm{c}<6.0 \%, 6.0-6.4 \%$ and $\geq 6.5 \%$ was: retinopathy: 3.4\% (95\% CI: 1.8-5.4\%), 2.3\% (95\% CI: 1.6-3.2\%) and 7.8\%(95\% CI: 5.7-10.3\%); nephropathy: $7.1 \%$ (95\% CI: $1.7-15.9 \%$ ), $9.6 \%$ (95\% CI: $0.8-26.4 \%$ ) and $17.1 \%$ (95\% CI: $1.0-46.9 \%$ ); neuropathy: $2.1 \%$ (95\% CI: $0.0-6.8 \%$ ), $3.4 \%$ (95\% CI: $0.0-11.6 \%$ ) and 2.8\% (95\% CI: 0.0-12.8\%). Multivariable meta-regression showed HbA1c $\geq 6.5 \%$ (OR: 4.05; 95\% CI: $1.92-8.57 \%$ ), age $>55$ (OR: 3.23; 95\% CI 1.81-5.77), and African-American race (OR: 10.73; 95\% CI: 4.34-26.55), to be associated with higher retinopathy prevalence. Marked heterogeneity in prevalence estimates was found across all metaanalyses (Cochran's $Q$-statistic $p<0.0001$ ).

Conclusions The prevalence of nephropathy and moderate retinopathy was increased in subjects with HbAlc values $\geq 6.5 \%$ confirming the high specificity of this value for diagnosing T2DM; however, at HbAlc $<6.5 \%$ retinopathy increased at age $>55$ years and, most strikingly, in African-Americans, suggesting there may be excess microvascular complication prevalence (particularly nephropathy) in individuals below the diabetes diagnostic threshold.
\end{abstract}

Keywords HbA1c · Type 2 diabetes $\cdot$ Microvascular complications

Managed by Antonio Secchi.

Stephen L Atkin and W. Garry John are Joint senior authors.

Electronic supplementary material The online version of this article (https://doi.org/10.1007/s00592-020-01606-5) contains supplementary material, which is available to authorized users.

Extended author information available on the last page of the article

\section{Introduction}

The prevalence of diabetes has reached epidemic proportions globally, with 424.9 million affected adults (20-79 y), representing $8.8 \%$ of the global adult population. Current projections indicate that this figure will rise to 628.6 million by the year 2045 , affecting almost $10 \%$ of the worldwide adult population [1]. Type 2 diabetes (T2DM) accounts for 
the vast majority (90-95\%) of diabetes cases and is commonly characterized by the inability of pancreatic beta cells to meet the demand for insulin secretion due to a relative deficit of functional beta cells in a setting of peripheral insulin resistance. There has been much debate over the years as to how T2DM should be diagnosed; what should be measured, and the diagnostic targets have changed, being refined as our understanding of the disease has improved along with improvement in analytical methods. The diagnostic criteria for T2DM are established [2], but it is clear that a continuum in blood glucose level exists from normoglycemia to frank diabetes. As such, in 1997 and 2003, the Expert Committee on Diagnosis and Classification of diabetes mellitus recognized a cohort of subjects whose glucose levels did not meet the criteria for diabetes but were too high to be considered as normal [3, 4]; this "prediabetic" group exhibited impaired fasting glucose (IFG) [fasting plasma glucose (FPG) levels of 100-125 mg/dL (5.6-6.9 mmol/L) and/or impaired glucose tolerance (IGT)] defined as a 2-h plasma glucose following a $75 \mathrm{~g}$ oral glucose tolerance test (OGTT) of $140-199 \mathrm{mg} / \mathrm{dL}(7.8-11.0 \mathrm{mmol} / \mathrm{L})]$ and represents individuals at high risk for development of T2DM.

Hemoglobin A1c (HbA1c) is considered key for assessing glycemic control in patients known to have diabetes, and several prospective studies using $\mathrm{HbA} 1 \mathrm{c}$ have shown a strong, continuous association between $\mathrm{HbAlc}$ and the development of diabetes and complications [5-7]. An International Expert Committee (IEC) recommended an $\mathrm{HbA1c}$ level of $6.5 \%(48 \mathrm{mmol} / \mathrm{mol})$ as the diagnostic threshold for T2DM diagnosis [8], purporting that individuals with HbA1c levels above this cutoff have a much higher probability of having retinopathy than those below. Both the American Diabetes Association (ADA) and, subsequently, the World Health Organization (WHO) endorsed this opinion, which was entirely based upon the risk of observing diabetic retinopathy, without consideration for other diabetic microvascular complications; however, the subject has to have had diabetes for a period of time for microvascular complications to develop that may occur at a lower HbA1c than $6.5 \%$.

Key studies contributing to the IEC/ADA/WHO diagnostic threshold decision were the results of the cross-sectional Evaluation of Screening and Early Detection Strategies for Type 2 Diabetes and Impaired Glucose Tolerance (DETECT-2) study [9] and three epidemiological studies undertaken in the 1990s on Pima Indians, Egyptians and US subjects enrolled in the National Health and Nutrition Examination Survey (NHANES) study $[3,10,11]$.

The current $\mathrm{HbA} 1 \mathrm{c}$ threshold was based on data available at the time of these groups' reports and, even at the time, there was debate as to whether a level of $6.5 \%$ (48 mmol/ mol) may be too high since, in many studies, it identified fewer patients as having diabetes than the traditional blood glucose criteria [12]. Since then, a number of studies have been performed with the aim of better characterizing the HbA1c threshold for prevalent or incident retinopathy. The studies prior to 2013 were summarized in a publication by Kowall and Rathmann who looked at retinopathy, nephropathy and neuropathy [13]; since this time, there have been a number of relevant publications which can now be considered.

The key aims of this study were to perform a contemporary systematic review and meta-analysis to verify the HbA1c cutpoint of $6.5 \%$ ( $48 \mathrm{mmol} / \mathrm{mol}$ ) for the diagnosis of T2DM using currently available retinopathy data and, secondly, to extend the analysis to establish the prevalence of nephropathy and neuropathy at differing levels of $\mathrm{HbA} 1 \mathrm{c}$.

\section{Methods}

\section{Data sources and search strategy}

This systematic review was guided by the Cochrane Collaboration Handbook [14], and followed the Preferred Reporting Items for Systematic Reviews and Meta-analyses (PRISMA) guidelines [15]. The PRISMA checklist is shown in Supplementary Table 1. A comprehensive systematic search for literature was conducted in the academic databases PubMed, Embase, Cochrane, Scopus, CINAHL and in sources for grey literature in October 2019 (Supplementary Table 2).

Pre-searches to identify relevant search terms, search strategies and information sources were performed in May-October 2019. PubMed's MeSH was used to systematically identify search terms that encompass the variations in terminology for glycated hemoglobin, including thresholds or cutpoints, as well as terms that describe diabetic microvascular complications (Tables 1,2,3). The search strategy developed in PubMed was replicated in all databases with eventual search terms or technical variations documented (Supplementary Table 2). The PRESS peer review of electronic search strategies: 2015 guideline statement was used to peer review the search string [16].

All selected search terms were searched in a combination of "Abstract" and "Article Title" (alternatively "Topic" or "Title, Abstract and Keyword") and in MeSH/Subject Headings/Thesaurus when available. A publication year filter to include studies from 1990 up to the search date was applied to account for the predominant lack of standardized/ harmonized $\mathrm{HbA} 1 \mathrm{c}$ measurement before this time. In order to ensure literature saturation and inclusion of pre-indexed materials, no additional filters or limitations were included.

In addition to the search in academic databases, Open Grey, Clinical Trials.gov, The New York Academy of Medicine-Grey Literature Report and ProQuest Dissertation and Theses were searched for grey literature. Hand screening of 


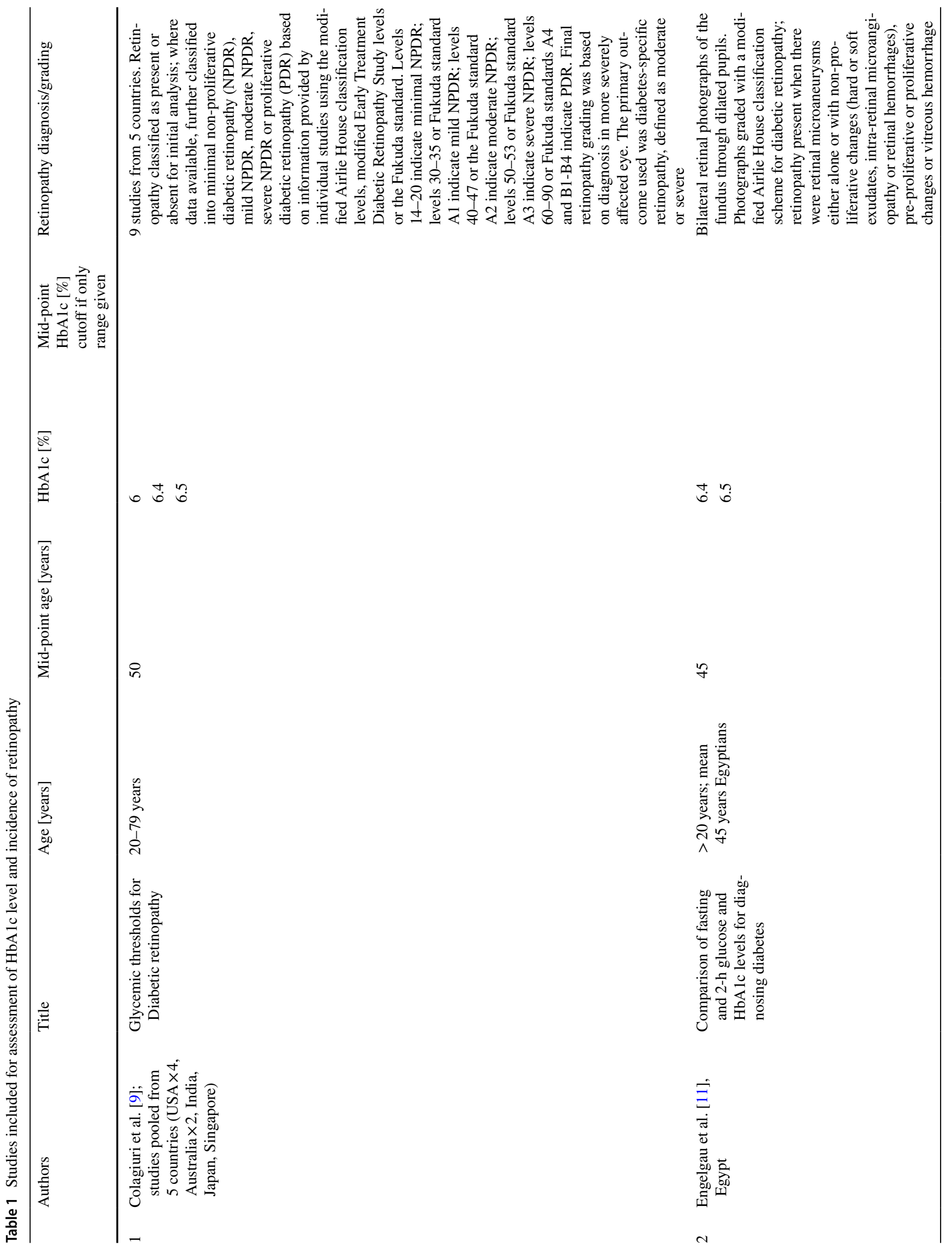




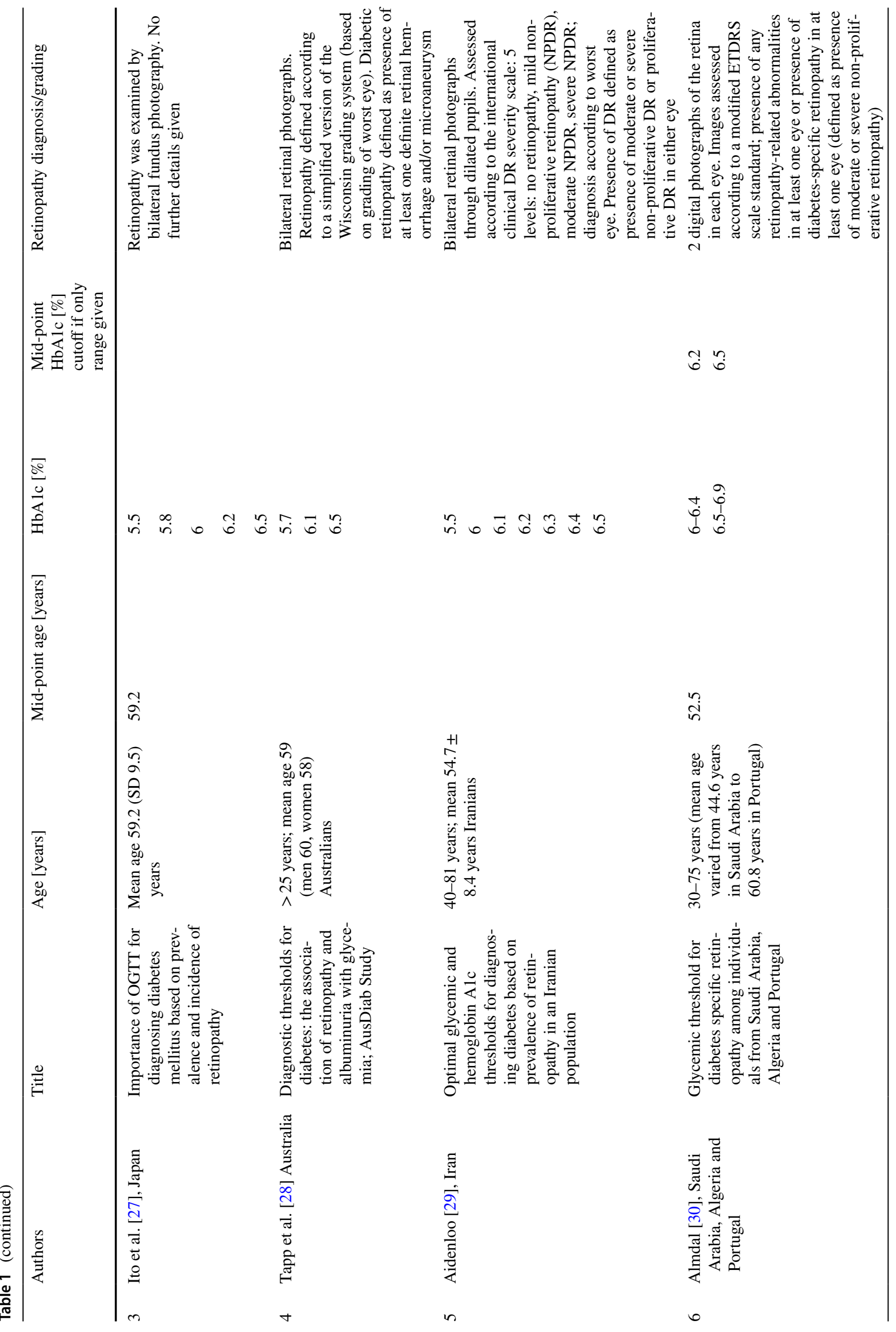




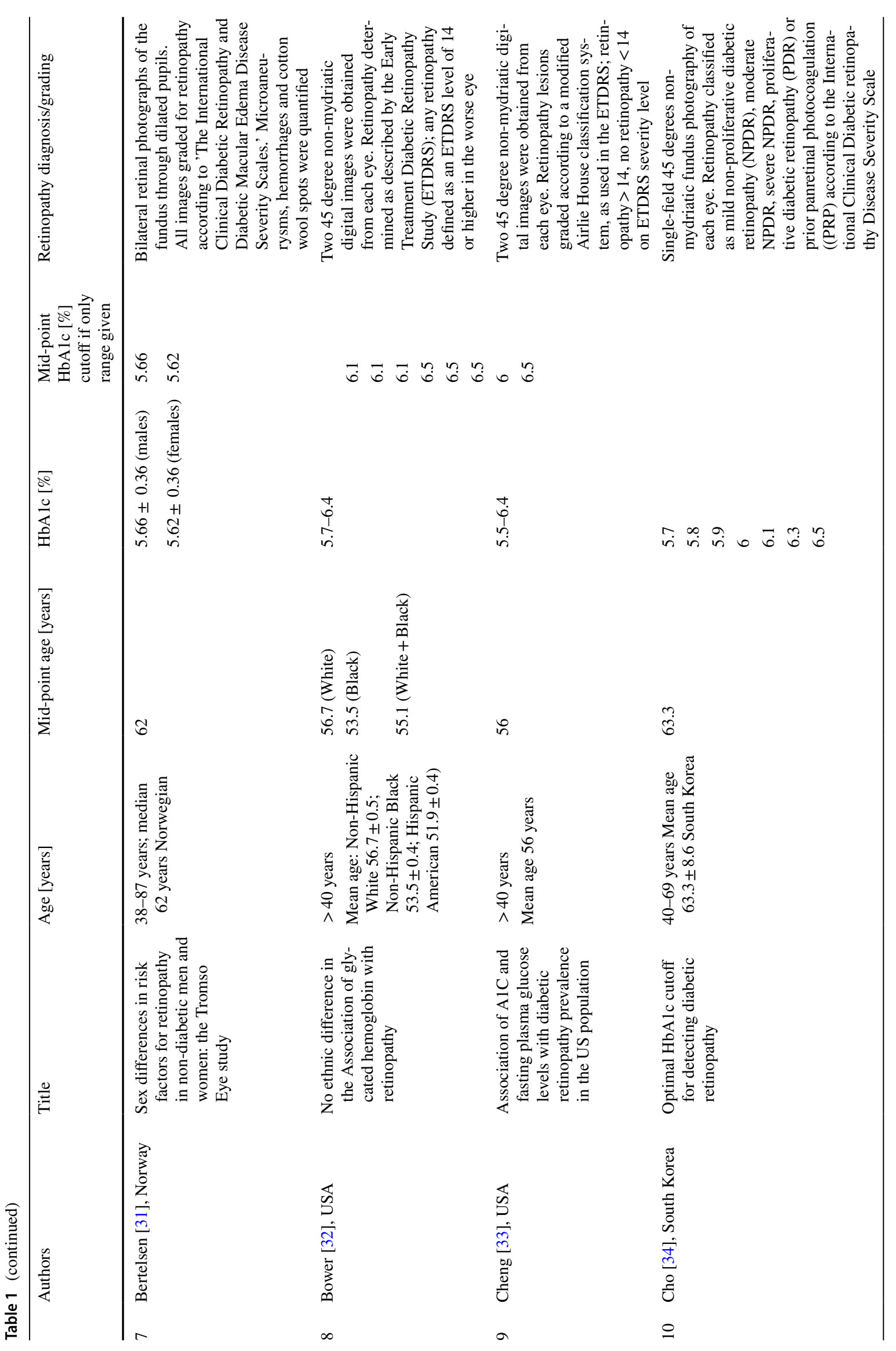




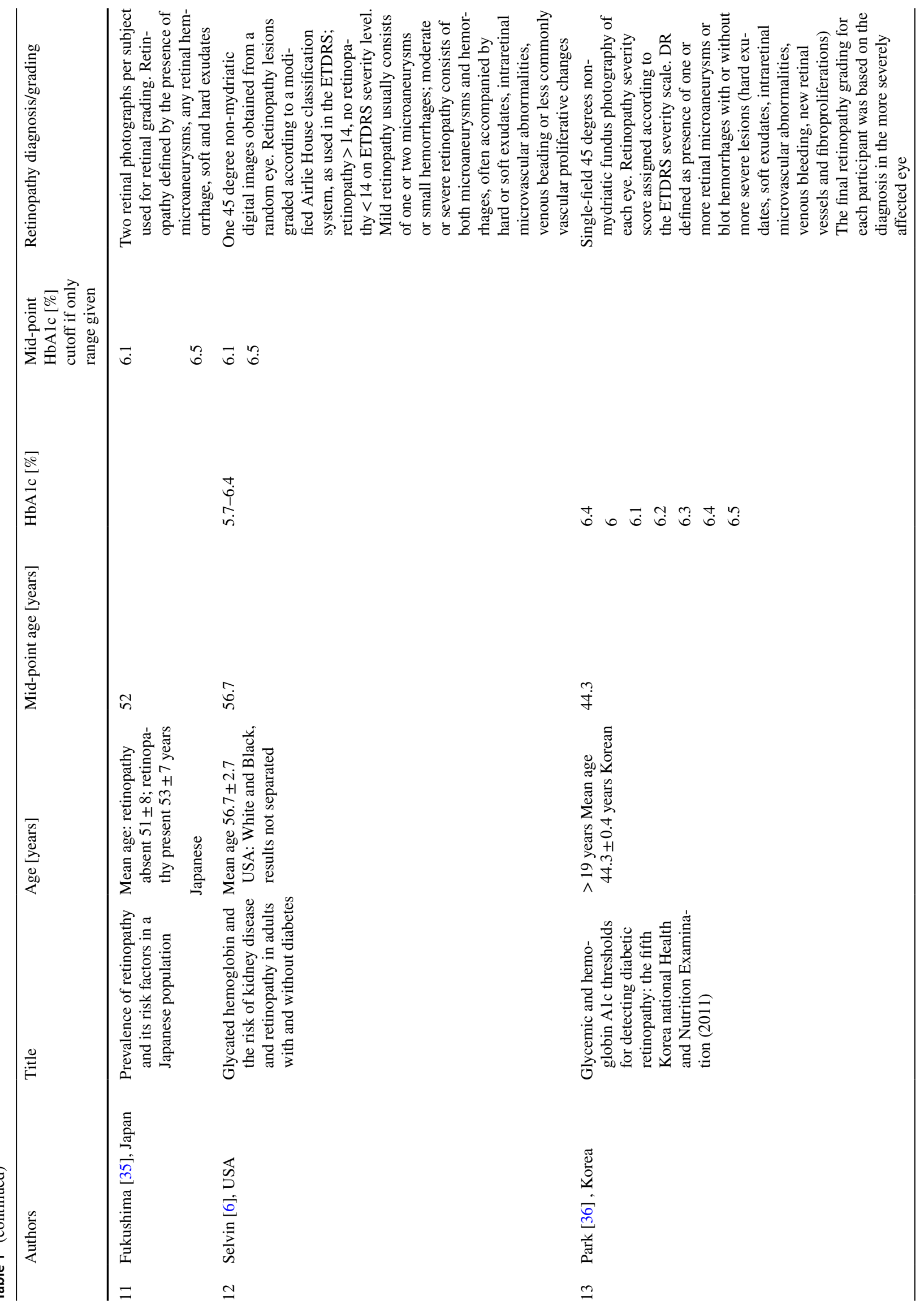




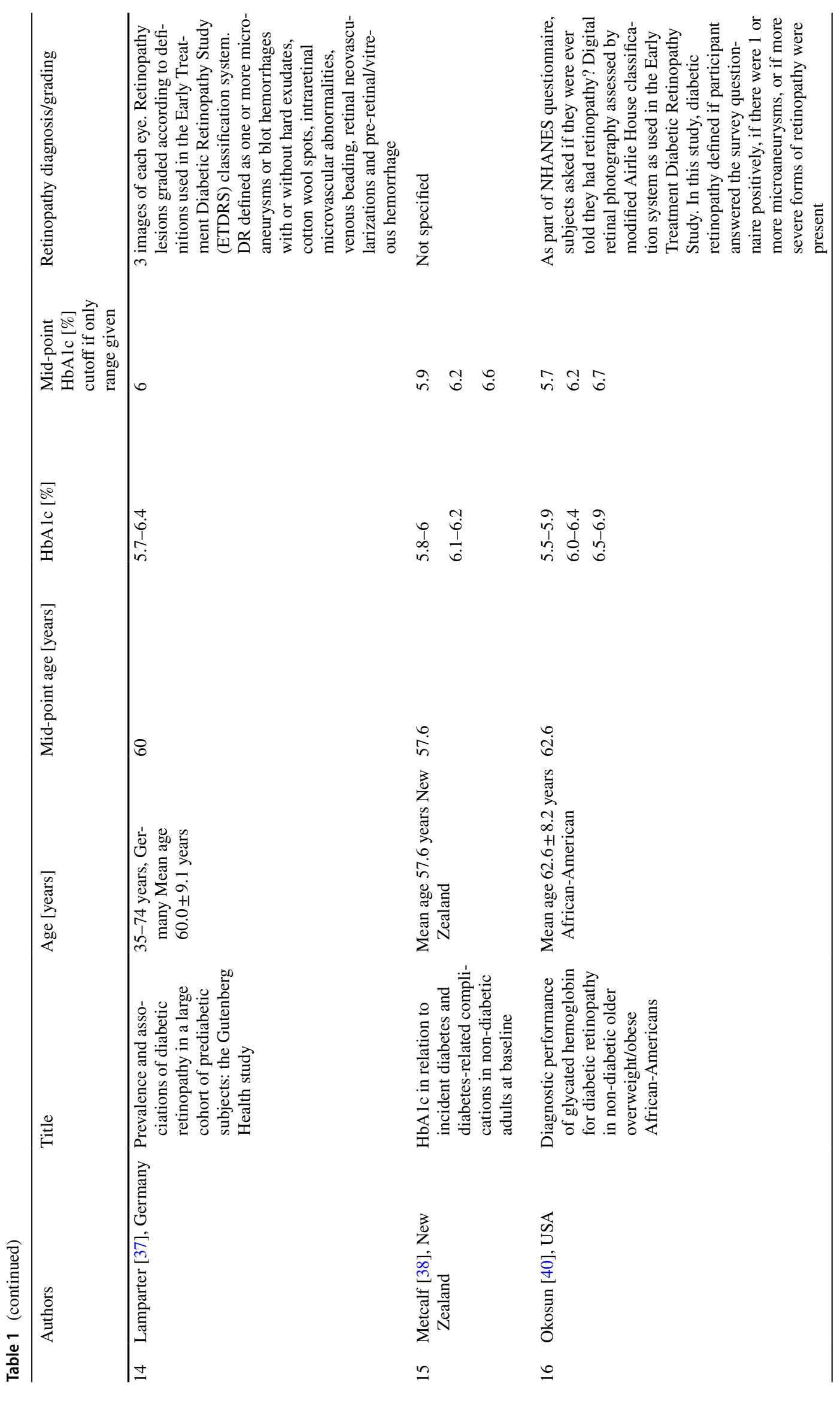




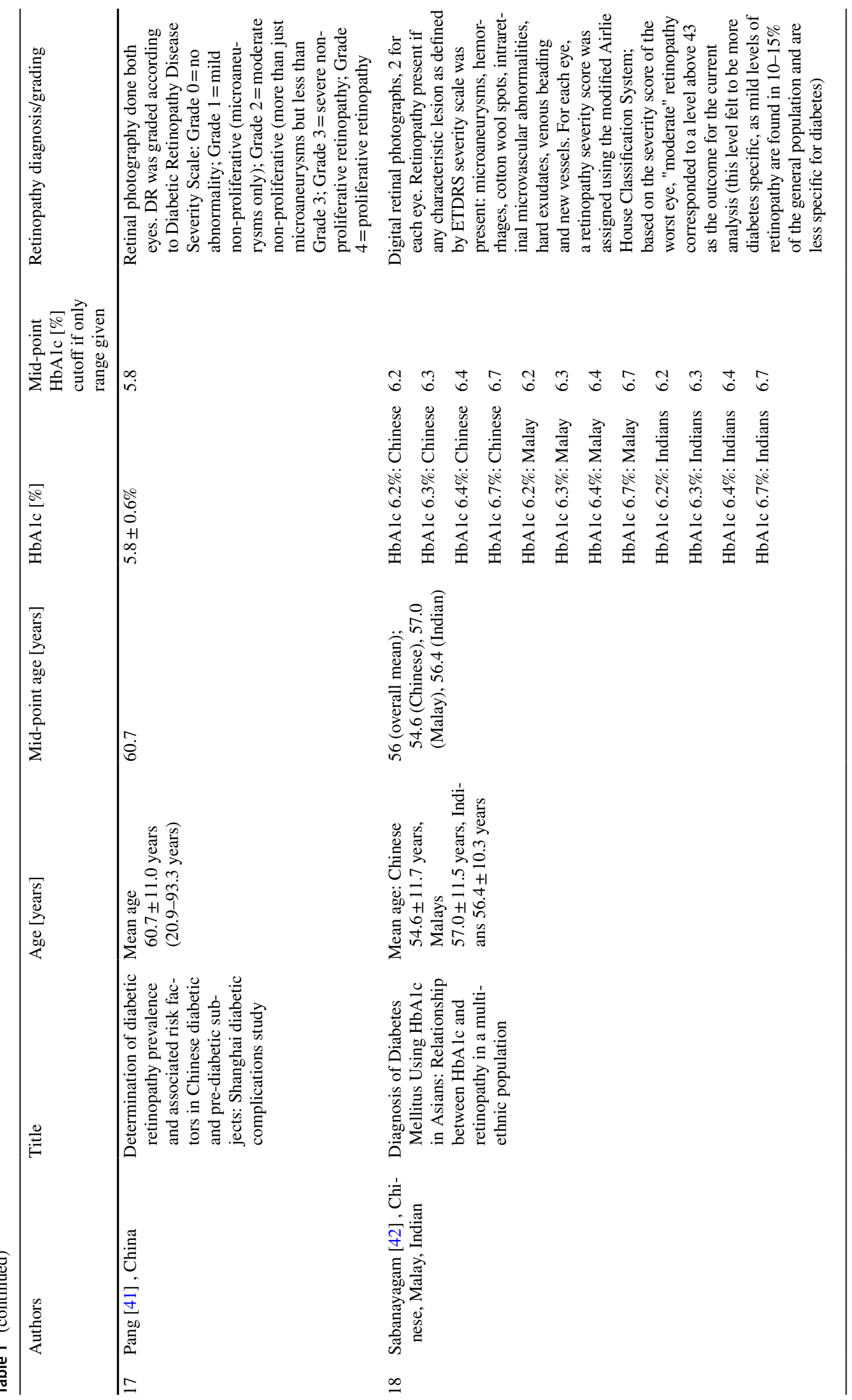




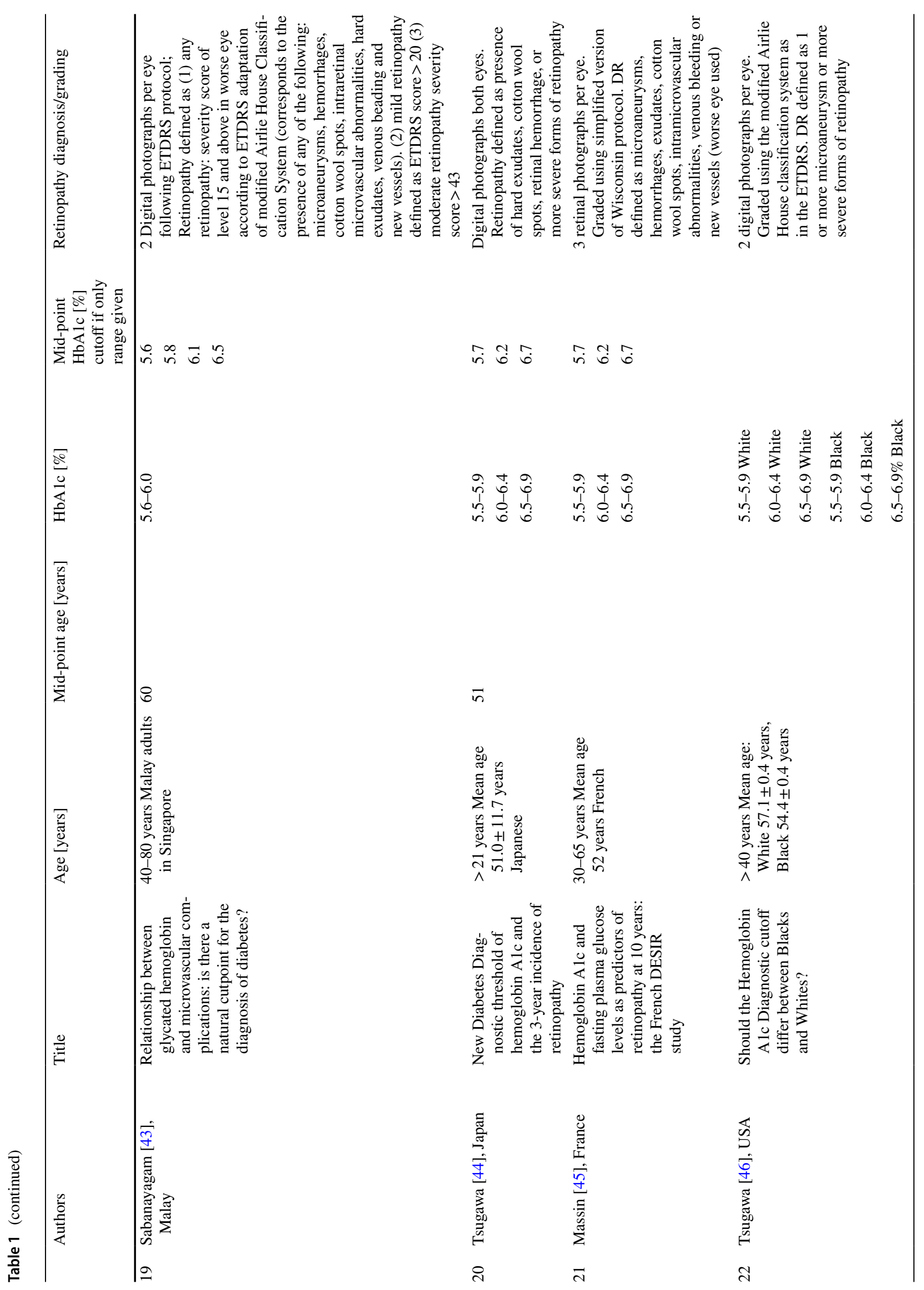




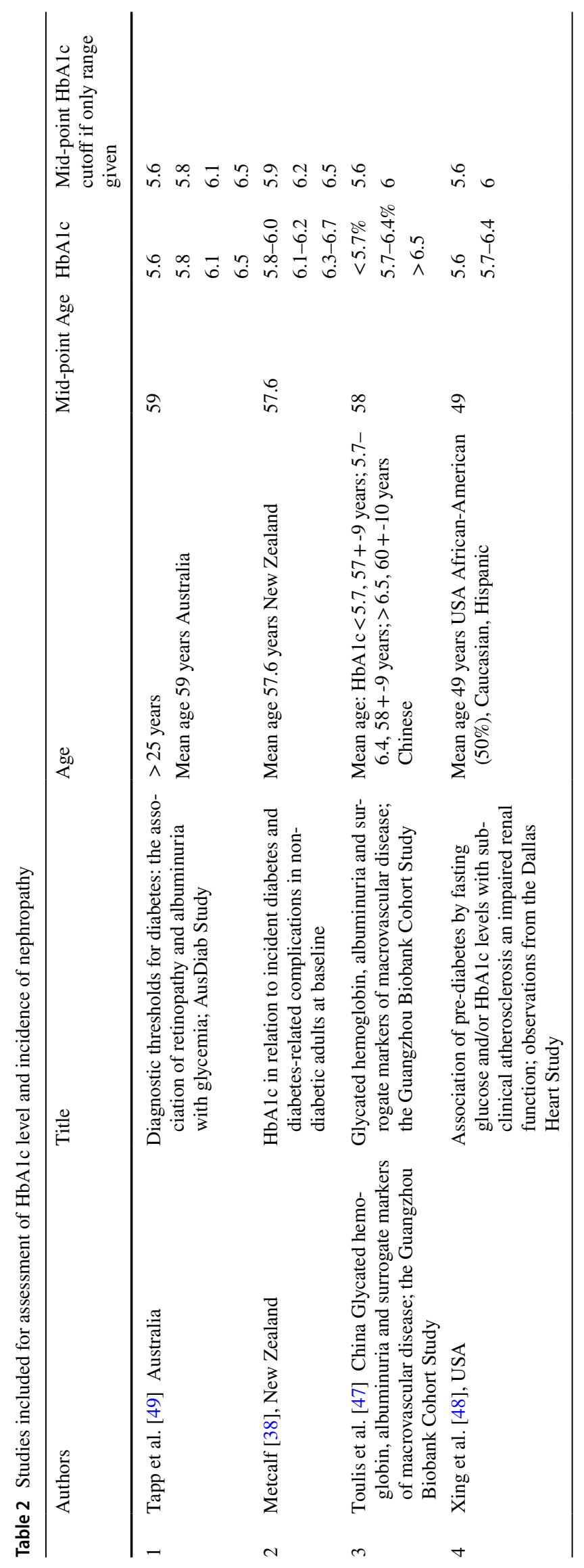


the references lists of all studies selected to be included in the review was also conducted.

A full search log including search technical details, results and notes about search term variations/translations for all databases can be found in Supplementary Table 2.

A review protocol for this study was registered in the Prospero international prospective register of systematic reviews: https://www.crd.york.ac.uk/prospero/display_recor d.php?RecordID=99410PROSPERO2018CRD4201809941 0 .

\section{Study selection}

Search results were imported into the Covidence systematic review tool where duplicate publications were identified and duplicates excluded. Study eligibility was independently determined by two investigators (AEB and SLA). Where there was a discrepancy, both investigators revisited the publication in question, discussed the results with the group and re-entered their decision into the database.

The criterion for inclusion was for a publication to report the prevalence of microvascular complications by levels of $\mathrm{HbA}$ 1c. More specifically, studies were only considered if they provided a prevalence measure for a microvascular complication stratified by $\mathrm{HbA} 1 \mathrm{c}$ of $<6 \%(<42 \mathrm{mmol} / \mathrm{mol})$, $6-6.4 \%(42-47 \mathrm{mmol} / \mathrm{mol})$ and $\geq 6.5 \%(48 \mathrm{mmol} / \mathrm{mol})$ in the same study. The reason for that is to ensure rigor in the association with microvascular complications. Exclusion criteria were studies that did not report microvascular complications by different HbA1c level and those published before 1990.

For terminology, a "publication" is a document containing a relevant outcome measure, while a "study" indicates all details pertaining to a specific outcome measure-one publication may contribute multiple studies. A study, such as "prevalence of retinopathy," could include multiple stratified "measures," such as prevalence by age group.

\section{Data extraction and quality assessment}

Following screening of records for eligibility, eligible studies had full-text screening (Supplementary Figure 1). Extracted variables included: author(s), publication title, year(s) of data collection, publication year, country of origin, country of survey, study design, study sampling procedure, study population and its characteristics (e.g., sex, age and ethnicity), sample size, HbA1c measurement method, HbA1c stratification outcome measures, complications, retinal photography method, number of eyes photographed, determination of albumin creatinine ratio, measure of peripheral neuropathy. Two investigators (AEB and SLA) independently assessed the full-text articles and determined the eligibility of studies for inclusion in the systematic review.

\section{Quality assessment}

Risk of bias (ROB) and precision assessments were performed for all studies included in the review. Guided by the Cochrane approach [17], studies were classified as having "low" vs. "high" ROB on two quality domains assessing (1) consistency in $\mathrm{HbA} 1 \mathrm{c}$ diagnostic measurement across all study participants (consistent vs. not consistent) and (2) rigor of sampling methodology (probability-based vs. nonprobability-based). Studies with unavailable information for any given domain were classified as having "unclear" ROB for that domain. Studies including at least 100 participants were considered as having higher precision. For a prevalence of microvascular complications of $1 \%$ (see prevalence by HbA1c in Table 1) and a sample size of 100 , the $95 \%$ confidence interval $(95 \% \mathrm{CI})$ is $0-5 \%$, an acceptable CI for the

Table 3 Studies included for assessment of HbA1c level and incidence of neuropathy

\begin{tabular}{|c|c|c|c|c|c|c|}
\hline & Authors & Title & Age & Mid-point Age & $\mathrm{HbA1c}$ & $\begin{array}{l}\text { Mid-point } \mathrm{HbA1c} \\
\text { cutoff if only range } \\
\text { given }\end{array}$ \\
\hline 1 & $\begin{array}{l}\text { Metcalf PA [38], New } \\
\text { Zealand }\end{array}$ & $\begin{array}{l}\text { HbA1c in relation to } \\
\text { incident diabetes and } \\
\text { diabetes-related compli- } \\
\text { cations in non-diabetic } \\
\text { adults at baseline }\end{array}$ & $\begin{array}{l}\text { Mean age } 57.6 \text { years New } \\
\text { Zealand }\end{array}$ & 57.6 & $\begin{array}{l}5.8-6.0 \\
6.1-6.2 \\
6.3-6.7\end{array}$ & $\begin{array}{l}5.9 \\
6.1 \\
6.5\end{array}$ \\
\hline 2 & $\begin{array}{l}\text { Kurisu et al. [50] poster, } \\
\text { Japan }\end{array}$ & $\begin{array}{l}\text { Polyneuropathy or neu- } \\
\text { ropathic pain did not } \\
\text { increase at prediabetic } \\
\text { stage in a Japanese } \\
\text { population }\end{array}$ & $\begin{array}{l}\text { Mean age } 62.1 \text { years } \\
\text { Japanese }\end{array}$ & 62.1 & $\begin{array}{l}5.9 \\
6.2\end{array}$ & \\
\hline 3 & Tapp [49] Australia & $\begin{array}{l}\text { Foot complications in type } \\
2 \text { diabetes: an Australian } \\
\text { population-based study }\end{array}$ & $\begin{array}{l}>25 \text { years Mean age: neu- } \\
\text { ropathy } 73 \pm 10 \text { years; no } \\
\text { neuropathy } 62 \pm 12 \text { years } \\
\text { Australia }\end{array}$ & 66.5 & $\begin{array}{l}\text { ND IFG/IGT } \\
\text { Diabetic }\end{array}$ & $\begin{array}{l}5.9 \\
6.2 \\
6.5\end{array}$ \\
\hline
\end{tabular}




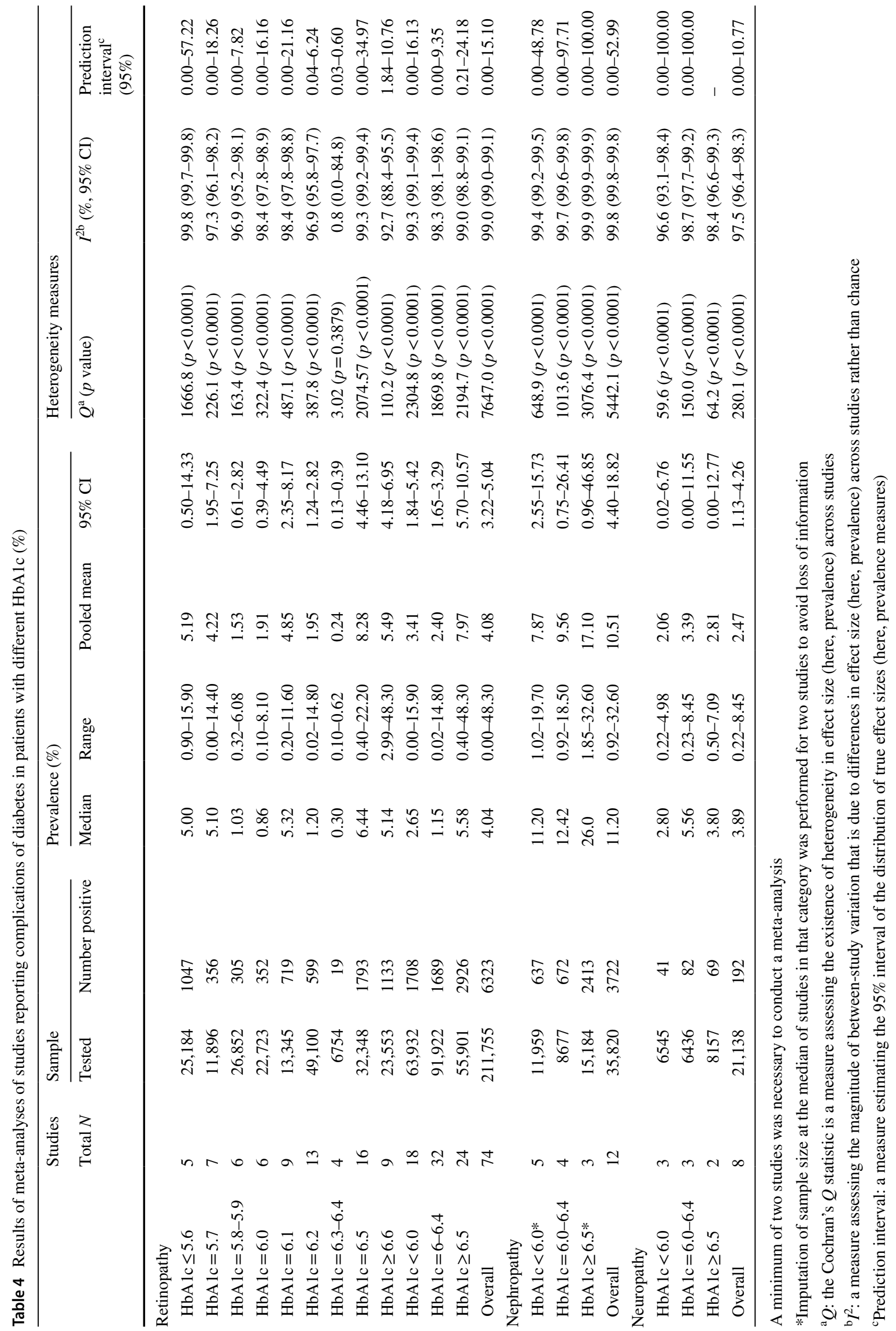


prevalence of microvascular complications (a lower sample size is needed to detect a higher prevalence). Results of the quality assessment are shown in Supplementary Tables 3 and 4 .

\section{Data synthesis and analysis}

\section{Statistical analysis}

\section{Meta-analysis methodology}

Meta-analyses were conducted to estimate the pooled mean of diabetes complications in relation to the stratified $\mathrm{HbA1c}$ values (extracted overall outcome measures for a specific HbA1c category, such as 6.0-6.4, were substituted with stratified measures such as by sub-levels of HbA1c, that is $6.0,6.1,6.2 \ldots$, or population characteristics). Forest plots were constructed to visualize prevalence measures and $95 \%$ confidence intervals (CIs) associated with each of the three outcomes of interest (retinopathy, nephropathy and neuropathy). Estimates for the pooled mean prevalence and 95\% CIs were then calculated using random-effects metaanalyses. Here, variances of prevalence measures were first stabilized using a Freeman-Tukey-type arcsine square-root transformation $[18,19]$. Inverse variance weighting $[19,20]$ was subsequently applied prior to pooling estimates using a DerSimonian-Laird random-effects model [21]. This model assumes a normal distribution for true effect sizes (prevalence) across studies and thus factors in sampling variation and true heterogeneity in effect size [22].

A heterogeneity assessment was further conducted using Cochran's $Q$ statistic to confirm existence of heterogeneity across studies and $\mathrm{I}^{2}$ to quantify magnitude of between-study variation that is due to true differences in effect size rather than chance [22, 23].

Meta-analyses were implemented in R version 3.4.2 [24].

\section{Meta-regression methodology}

Associations with prevalence and sources of between-study heterogeneity were identified using random-effects univariable and multivariable meta-regression analyses. Predictors considered a priori included: HbA1c levels, age and race. Factors associated with prevalence at $p$ value $\leq 0.10$ in univariable analysis were eligible for inclusion in the multivariable model. In the latter, a $p$ value $\leq 0.10$ but $>0.05$ was considered as showing "good evidence" for an association with prevalence, while a $p$ value $\leq 0.05$ indicated strong evidence for an association with prevalence.

The magnitude of the association between these predictors and prevalence was determined by calculating, in the univariable analysis, odds ratios (ORs) and their associated
95\% CIs, and in the multivariable analysis, by calculating adjusted odds ratios (AORs) and their associated 95\% CIs.

Meta-regressions were conducted in Stata/SE version 13 [25] using the metareg package [26].

\section{Results}

\section{Literature search}

A total of 12,845 references were identified through the literature search and uploaded to the systematic review software Covidence for de-duplication and screening. 9370 references ( 9324 from the database search and 46 from the grey literature search) qualified for title and abstract screening after de-duplication. The screening process in Covidence software was blinded. Of the 9370 references, 9206 records were excluded. 164 full-text articles were then assessed for eligibility; of those 135 were excluded because of insufficient details of the relationship of the microvascular complication to the $\mathrm{HbA} 1 \mathrm{c}$ values less than $6.5 \%$ ( $48 \mathrm{mmol} / \mathrm{mol})$. Twenty nine publications remained eligible for inclusion in the systematic review, 22 relating to retinopathy (Table 1) $[6,9,11,27-46] ; 4$ relating to nephropathy (Table 2) $[28,38$, $47,48]$ and 3 relating to neuropathy (Table 3 ) [38, 49, 50]. No additional relevant references were identified in the hand searching of the reference lists of the 29 included studies. The retinopathy studies contributed 74 stratified measures for the quantitative meta-analysis according to $\mathrm{HbAlc}$ as detailed above.

\section{Study characteristics}

The definitions of retinopathy, nephropathy and neuropathy used in each study are shown in Tables 1, 2 and 3, respectively.

Diabetic retinopathy, defined as diabetes-related damage to the retina, is classified into early stage non-proliferative diabetic retinopathy (NPDR, comprising microaneurysms and macular edema) and second-stage proliferative diabetic retinopathy (PDR, comprising neovascularization and vitreous hemorrhages) and fundal photography is required for diagnosis [51]. HbA1c was stratified into the following categories in each study: $<6 \%(<42 \mathrm{mmol} / \mathrm{mol}),=6-6.4 \%$ $(42-47 \mathrm{mmol} / \mathrm{mol})$ and $\geq 6.5 \%(\geq 48 \mathrm{mmol} / \mathrm{mol})$.

The forest plot for retinopathy is shown in Fig. 1 . The median prevalence of retinopathy was overall $4.0 \%$ (range: 0-48.3\%), but varied according to HbA1c levels (Table 4). It was $2.7 \%$ (range: $0-15.9 \%$ ) for $\mathrm{HbA} 1 \mathrm{c}<6.0 \%$ ( $<42 \mathrm{mmol} / \mathrm{mol}$ ), $1.2 \%$ (range: $0.2-14.8 \%$ ) for $\mathrm{HbA} 1 \mathrm{c}$ 6.0-6.4\% $42-47 \mathrm{mmol} / \mathrm{mol}$ ) and 5.6\% (range: $0.4-48.3 \%$ ) for $\mathrm{HbAlc} \geq 6.5 \%$ ( $\geq 48 \mathrm{mmol} / \mathrm{mol})$. 
Fig. 1 Forest plot showing results of the meta-analysis for retinopathy prevalence. Retinopathy prevalence stratified by HbA1c levels

\begin{tabular}{|c|c|c|c|c|c|c|}
\hline Author, Year & Retinopathy positive & Sample size & $\begin{array}{c}\text { Events per } 100 \\
\text { observations }\end{array}$ & W(Random) & $\operatorname{Prev}(\%)$ & $95 \% \mathrm{Cl}$ \\
\hline \multicolumn{7}{|l|}{ HbA1C less than 6.0} \\
\hline Okosun, 2016 & 14 & 97 & 1 & $1.1 \%$ & 14.43 & [ 8.12; 23.03] \\
\hline Cho, 2013 & 0 & $247+$ & & $1.3 \%$ & 0.00 & {$[0.00 ; 1.48]$} \\
\hline Cho, 2013 & 1 & $260 \div$ & & $1.3 \%$ & 0.38 & {$[0.01 ; 2.12]$} \\
\hline Cho, 2013 & 1 & $309+$ & & $1.3 \%$ & 0.32 & {$[0.01 ; 1.79]$} \\
\hline Tsugawa, 2012 & 34 & 352 & 1 & $1.3 \%$ & 9.66 & {$[6.78 ; 13.24]$} \\
\hline Sabanayagam, 2009 & 35 & 700 & 1 & $1.4 \%$ & 5.00 & {$[3.51 ; 6.89]$} \\
\hline Sabanayagam, 2009 & 61 & 1004 & 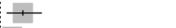 & $1.4 \%$ & 6.08 & {$[4.68 ; 7.74]$} \\
\hline Tsugawa, 2012 & 53 & 1034 & + & $1.4 \%$ & 5.13 & {$[3.86 ; 6.65]$} \\
\hline Aidenloo, 2016 & 2 & 1608 & & $1.4 \%$ & 0.12 & {$[0.02 ; 0.45]$} \\
\hline Massin, 2011 & 48 & $1608+$ & & $1.4 \%$ & 2.99 & {$[2.21 ; 3.94]$} \\
\hline Tapp et al, 2006 & 131 & 2182 & + & $1.4 \%$ & 6.00 & {$[5.04 ; 7.08]$} \\
\hline Pang, 2011 & 56 & 2460 & & $1.4 \%$ & 2.28 & {$[1.72 ; 2.95]$} \\
\hline Bertelsen, 2014 & 393 & 2474 & + & $1.4 \%$ & 15.89 & {$[14.47 ; 17.39]$} \\
\hline Bertelsen, 2014 & 464 & 3363 & + & $1.4 \%$ & 13.80 & {$[12.65 ; 15.01]$} \\
\hline Metcalf, 2017 & 84 & $5780=$ & & $1.4 \%$ & 1.45 & {$[1.16 ; 1.80]$} \\
\hline Tsugawa, 2012 & 76 & $6376+$ & & $1.4 \%$ & 1.19 & {$[0.94 ; 1.49]$} \\
\hline Ito et al, 2000 & 153 & 17039 & & $1.4 \%$ & 0.90 & {$[0.76 ; 1.05]$} \\
\hline Ito et al, 2000 & 102 & 17039 & & $1.4 \%$ & 0.60 & {$[0.49 ; 0.73]$} \\
\hline Random effects model & 1708 & $63932<$ & & $24.6 \%$ & 3.41 & {$[1.84 ; 5.42]$} \\
\hline
\end{tabular}

$\mathrm{HbA} 1 \mathrm{C}=6.0-6.4$

Tsugawa, 2012

Okosun, 2016

Almdal, 2014

Tsugawa, 2012

Cho, 2013

Cho, 2013

Fukushima, 2013

Cho, 2013

Massin, 2011

Bower, 2013

Lamparter, 2014

Bower, 2013

Cheng, 2009

Colagiuri et al, 2011

Colagiuri et al, 2011

Selvin, 2011

Sabanayagam, 2009

Tsugawa, 2012

Tapp et al, 2006

Aidenloo, 2016

Aidenloo, 2016

Bower, 2013

Aidenloo, 2016

Aidenloo, 2016

Aidenloo, 2016

Sabanayagam, 2014

Park, 2014

Metcalf, 2017

Sabanayagam, 2014

Sabanayagam, 2014

Ito et al, 2000

Ito et al, 2000

Random effects model

Heterogeneity: $I^{2}=98 \%, \tau^{2}=0.0055, \chi_{31}^{2}=1869.83(p=0)$

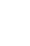

HbA1C of 6.5 or more

Okosun, 2016

Fukushima, 2013

Tsugawa, 2012

Park, 2014

Tsugawa, 2012

Almdal, 2014

Selvin, 2011

Cho, 2013

Tsugawa, 2012

Colagiuri et al, 2011

Bower, 2013

Engelgau et al, 1997

Bower, 2013

Massin, 201

Cheng, 2009

Tapp et al, 2006

Sabanayagam, 2009

Bower, 2013

Aidenloo, 2016

Sabanayagam, 2014

Sabanayagam, 2014

Sabanayagam, 2014

Metcalf, 2017

Ito et al, 2000

Random effects model

Heterogeneity: $I^{2}=99 \%, \tau^{2}=0.0113, \chi_{23}^{2}=2926$

Random effects model

$6323.03(p=0)$
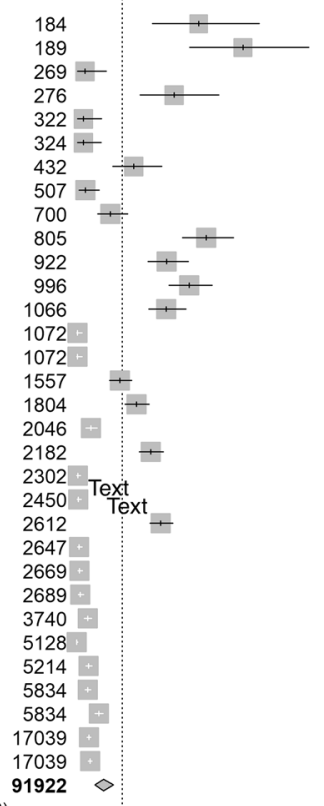

$1.2 \%$

$1.2 \%$
$1.3 \%$

$10.87 \quad[6.77 ; 16.29]$

14.81 [10.08; 20.69]

$0.74 \quad[0.09 ; 2.66]$

$8.70[5.65 ; 12.66]$

0.62 [0.08; 2.23]

$0.62[0.07 ; 2.21]$

$5.09 \quad[3.22 ; 7.61]$

$0.79 \quad[0.22 ; 2.01]$

$3.00 \quad[1.87 ; 4.55]$

$11.55[9.43 ; 13.97]$

$8.03 \quad[6.35 ; 9.97]$

8.03
$10.04[8.35 ; 9.97]$

$10.04 \quad[8.24 ; 12.08]$
$7.97 \quad[6.42 ; 9.77]$

$0.09 \quad[0.00 ; 0.52]$

$0.09 \quad[0.00 ; 0.52]$

3.85 [2.95; 4.93]

$5.32[4.33 ; 6.46]$

$1.27 \quad[0.83 ; 1.86]$

$6.60 \quad[5.59 ; 7.72]$

$0.13 \quad[0.03 ; 0.38]$

$0.16 \quad[0.04 ; 0.42]$

$\begin{array}{lll}0.16 & {[0.04 ; 0.42]} \\ 7.50 & {[6.52 ;} & 8.58]\end{array}$

$0.23 \quad[0.08 ; 0.49]$

$0.26 \quad[0.11 ; 0.54]$

$0.33 \quad[0.15 ; 0.63]$

$0.99 \quad[0.70 ; 1.36]$

$0.02 \quad[0.00 \cdot 0.11]$

$1.07 \quad[0.81 ; 1.39]$

$1.07[0.81,1.39]$

$0.99[0.76 ; 1.28]$

$1.99[1.65 ; 2.38]$

$1.10 \quad[0.95 ; 1.27]$

$1.20[1.04 ; 1.37]$
$2.40 \quad[1.65 ; 3.29]$

$44.2 \%$

Heterogeneity: $I^{2}=99 \%, \tau^{2}=0.0093, \chi_{73}^{2}=7047$.

Residual heterogeneity: $I^{2}=99 \%, \chi_{71}^{2}=6369.33(p=0)$

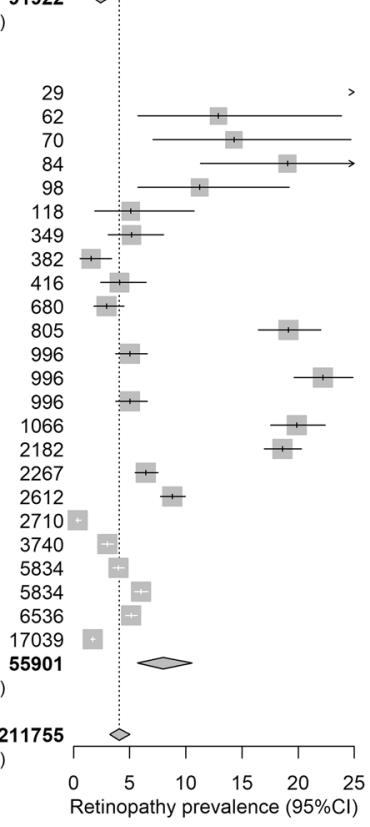

0.7\%
$1.0 \%$
$1.0 \%$
$1.1 \%$
$1.1 \%$
$1.2 \%$
$1.3 \%$
$1.3 \%$
$1.3 \%$
$1.4 \%$
$1.4 \%$
$1.4 \%$
$1.4 \%$
$1.4 \%$
$1.4 \%$
$1.4 \%$
$1.4 \%$
$1.4 \%$
$1.4 \%$
$1.4 \%$
$1.4 \%$
$1.4 \%$
$1.4 \%$
$1.4 \%$
$\mathbf{3 1 . 2} \%$

$48.28[29.45 ; 67.47]$ $12.90[5.74 ; 23.85]$ $14.29[7.07 ; 24.71]$ $19.05[11.30 ; 29.08]$ $11.22[5.74 ; 19.20]$ 5.08 [ $1.89 ; 10.74]$ $5.16[3.09 ; 8.03]$ $1.57 \quad[0.58 ; 3.39]$ $4.09 \quad[2.40 ; 6.46]$ $2.94 \quad[1.81 ; 4.51]$ $19.13[16.47 ; 22.02]$ $5.02[3.75 ; 6.57]$ $22.19[19.64 ; 24.90]$ $5.02[3.75 ; 6.57]$ $5.02[3.75 ; 6.57]$
$19.89[17.53 ; 22.41]$ $18.61[16.99 ; 20.30]$
$6.44[5.46 ; 7.53]$ $8.81[7.75 ; 9.96]$ $0.37 \quad[0.18 ; 0.68]$ $2.99[2.47 ; 3.59$ $3.99[3.51 ; 4.53]$ $5.14[4.62 ; 5.70]$ $1.70[1.51 ; 1.91]$
$\mathbf{7 . 9 7}[\mathbf{5 . 7 0} \mathbf{1 0 . 5 7}]$

$100.0 \%$

$4.08 \quad[3.22 ; 5.04]$ $19.89[17.53 ; 22.41]$ $2.99[2.47 ; 3.59]$ $6.00[5.40 ; 6.64]$ 


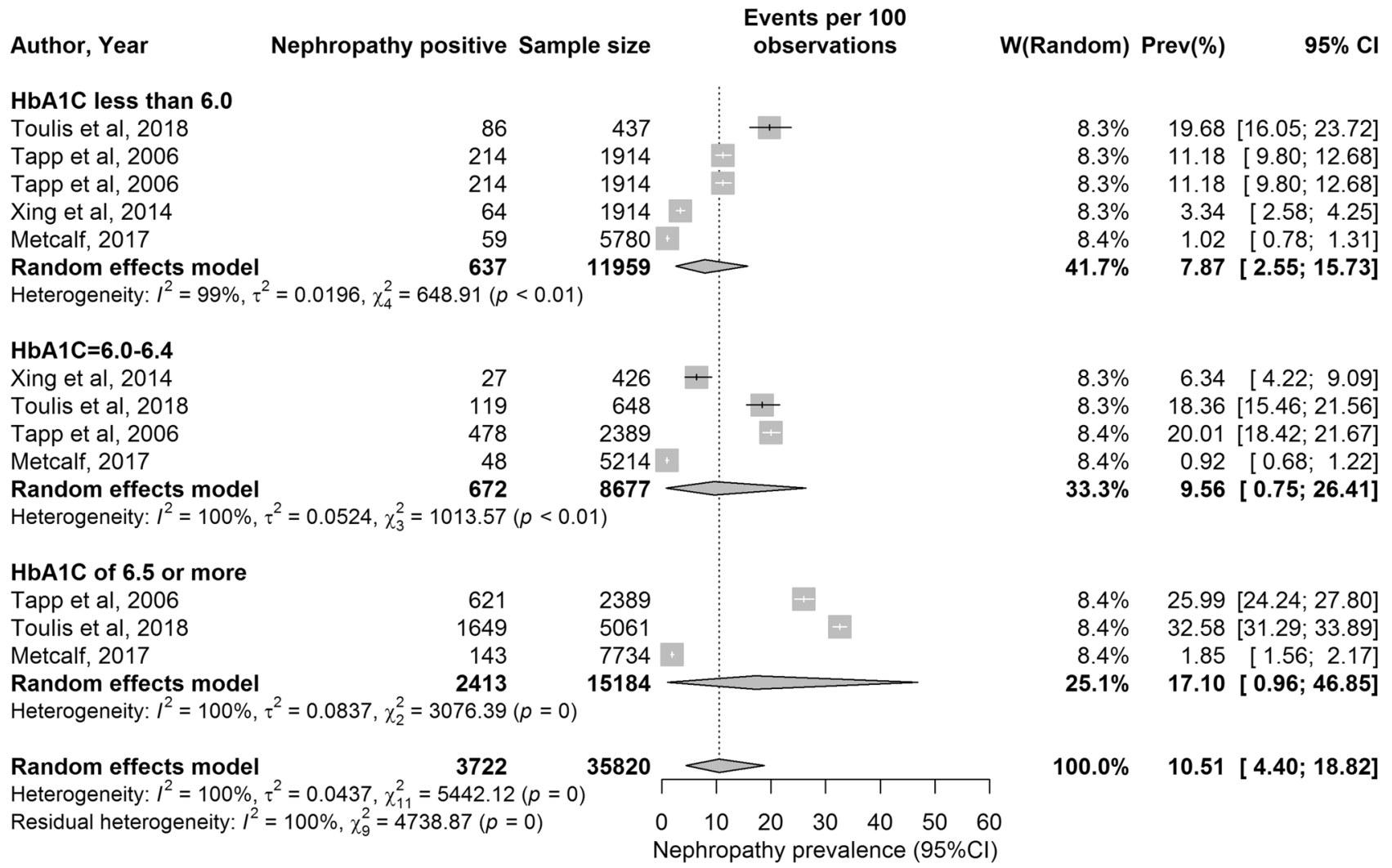

Fig. 2 Forest plot showing results of the meta-analysis for nephropathy prevalence. Nephropathy prevalence stratified by HbA1c levels

The forest plot for nephropathy is shown in Fig. 2. The median prevalence of nephropathy was assessed at $11.2 \%$ (range: 0.9-32.6\%). However, there was also variability based on $\mathrm{HbA1c}$ value, with a median of $7.3 \%$ (range: $1.0-19.7 \%)$ for $\mathrm{HbA} 1 \mathrm{c}<6.0 \%$ (<42 $\mathrm{mmol} / \mathrm{mol}), 12.4 \%$ (range: $0.9-18.5 \%$ ) for HbA1c $6.0-6.4 \%$ (42-47 mmol/ $\mathrm{mol}$ ) and $26.0 \%$ (range: $1.9-32.6 \%$ ) for $\mathrm{HbA} 1 \mathrm{c} \geq 6.5 \%$ ( $\geq 48 \mathrm{mmol} / \mathrm{mol}$ ) (Table 4 ).

The forest plot for neuropathy is shown in Fig. 3. The median prevalence for neuropathy was $3.9 \%$ (range: $0.2-8.5 \%$ ). It was $2.8 \%$ (range: $0.2-5.0 \%$ ) for $\mathrm{HbA} 1 \mathrm{c}<6.0 \%$ (<42 mmol/mol), $5.6 \%$ (range: $0.2-8.5 \%$ ) for $\mathrm{HbA} 1 \mathrm{c}$ 6.0-6.4\% (42-47 $\mathrm{mmol} / \mathrm{mol})$ and $3.8 \%$ (range: $0.2-8.5 \%$ ) for $\mathrm{HbAlc} \geq 6.5 \%$ ( $\geq 48 \mathrm{mmol} / \mathrm{mol}$ ) (Table 4$)$.

\section{Quality assessment}

Supplementary Tables 3 and 4 show the results of the summarized and study-specific quality assessments. In sum, $72.7 \%$ ( $n=16$ out of 22) of retinopathy studies, $50.0 \%(n=2$ out of 4 ) of nephropathy studies and $66.7 \%(n=2$ out of 3$)$ of neuropathy studies included at least 100 participants and therefore were considered as having higher precision.

Low risk of bias, assessed as consistency in measuring $\mathrm{HbA} 1 \mathrm{c}$ across study participants, was found in $81.8 \%$ of studies assessing retinopathy, all studies assessing nephropathy, and $66.7 \%$ of studies assessing neuropathy. The majority of studies assessing retinopathy (95.5\%) and all studies assessing nephropathy and neuropathy used probabilitybased sampling and hence were also classified as having low ROB on that quality domain.

Overall, studies reporting the prevalence of microvascular complications of T2DM were of acceptable quality: $81.8 \%$ of retinopathy studies, all nephropathy studies and $66.7 \%$ of neuropathy studies had low ROB on both quality domains. High ROB on both domains was found in only $4.5 \%$ of retinopathy studies and none of nephropathy or neuropathy studies.

\section{Meta-analysis results}

The pooled mean prevalence was estimated at $4.1 \%$ (95\% CI: $3.2-5.0 \%$ ) for retinopathy, $10.5 \%$ (95\% CI: 4.4-18.8\%) for nephropathy and $2.5 \%$ (95\% CI: $1.1-4.3 \%$ ) for neuropathy (Table 4 and Figs. 1, 2, 3).

There was evidence for heterogeneity in prevalence estimates across all meta-analyses (Table 4). $P$ value for Cochran's $Q$ statistic was almost always $<0.0001 . I^{2}$ was $>90 \%$ indicating that most variability is due to true differences in prevalence across studies rather than chance. 


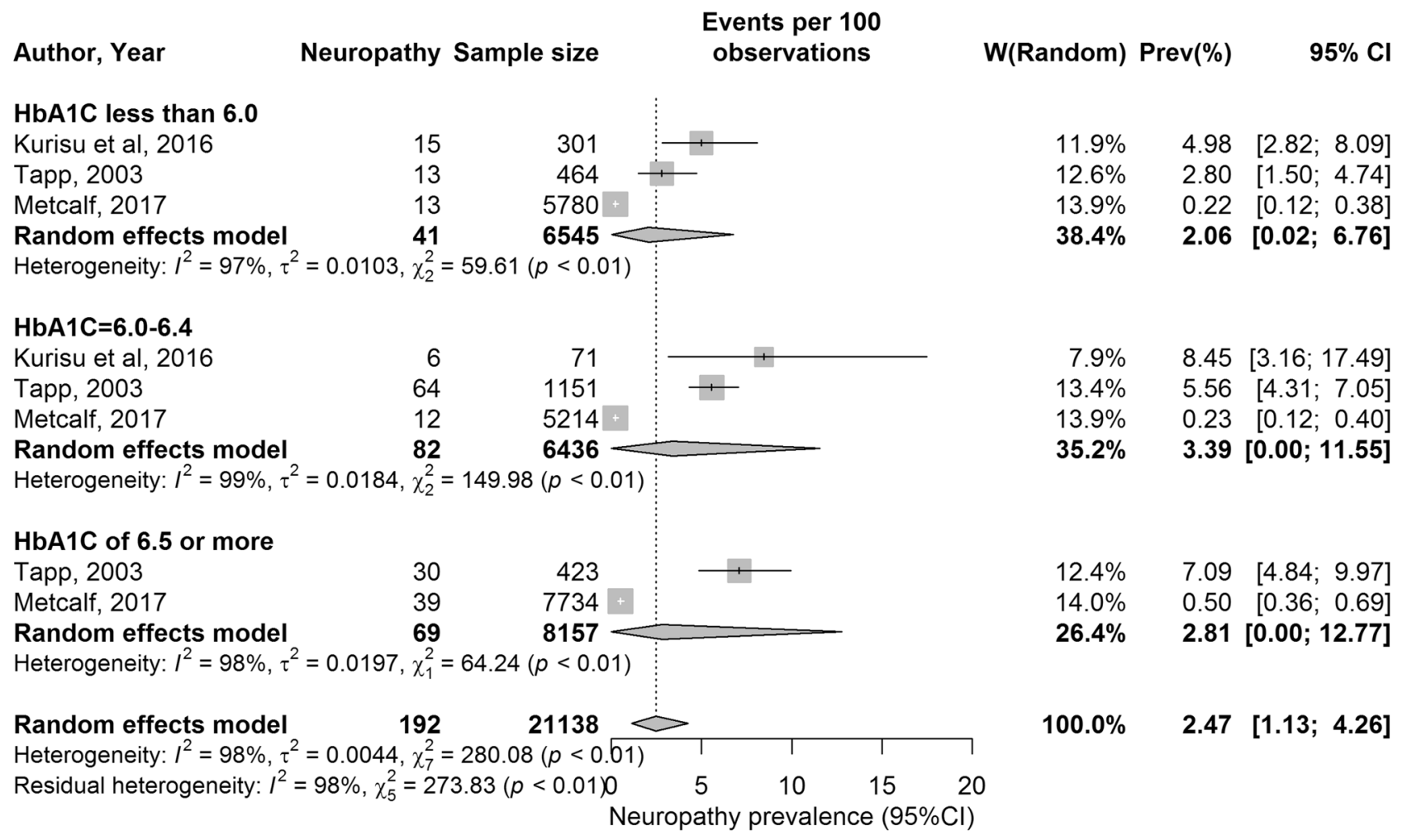

Fig. 3 Forest plot showing results of the meta-analysis for neuropathy prevalence. Neuropathy prevalence stratified by HbA1c levels

\section{HbA1c Level and risk of retinopathy}

For retinopathy, when the prevalence of complications was stratified according to $\mathrm{HbA} 1 \mathrm{c}$, using categories of $<6.0 \%$ ( $<42 \mathrm{mmol} / \mathrm{mol}$ ), $6.0-6.4 \%$ (42-46 $\mathrm{mmol} / \mathrm{mol}$ ) and $\geq 6.5 \%$ $(\geq 48 \mathrm{mmol} / \mathrm{mol})$, there was a distinct increase in retinopathy prevalence from a pooled mean of $3.41 \%$ (95\% CI: $1.84-5.42)$ in the $<6.0 \%(<42 \mathrm{mmol} / \mathrm{mol})$ stratum and a pooled mean of $2.40 \%$ (95\% CI: $1.65-3.29$ ) in the $6-6.4 \%$ $42-47 \mathrm{mmol} / \mathrm{mol})$ stratum to a pooled mean of $7.97 \%(95 \%$ CI: $5.70-10.57)$ in the $\geq 6.5 \%$ ( $\geq 48 \mathrm{mmol} / \mathrm{mol})$ stratum. The $\mathrm{J}$-shaped curve describing this association can be found in Fig. 4. The prevalence of retinopathy stratified in $0.1 \%$ increments is shown in Fig. 5. The latter analysis showed no trend of increasing retinopathy for $\mathrm{HbA} 1 \mathrm{c}$ ranging from 6.0 to $6.4 \%$, but a marked increase in prevalence at $\mathrm{HbA} 1 \mathrm{c}$ of $6.5 \%$ and greater.

\section{HbA1c Level and risk of nephropathy}

The albumin/creatinine ratio (expressed as $\mathrm{mg}$ albumin: mmol creatinine; ACR) is a sensitive indicator of kidney disease, and patients are classified according to the 2012 guidelines developed by the Kidney Disease: Improving Global Outcomes organization (KDIGO) [52] as: normal $<3 \mathrm{mg} /$ mmol (A1), moderate 3-30 mg/mmol (A2), severe > $30 \mathrm{mg}$ / mmol (A3; nephropathy). Notably, for nephropathy, the prevalence of this complication overall tended to be higher than that for retinopathy. Again, there was a distinct increase in nephropathy prevalence from a pooled mean of $7.12 \%$ (95\% CI: $1.68-15.85)$ in the $<6.0 \%(<42 \mathrm{mmol} / \mathrm{mol})$ stratum and a pooled mean of $9.56 \%$ (95\% CI: $0.75-26.41)$ in the $6-6.4 \%(42-47 \mathrm{mmol} / \mathrm{mol})$ stratum to a pooled mean of $17.10 \%$ (95\% CI: $0.96-46.85)$ in the $\geq 6.5 \%$ ( $\geq 48 \mathrm{mmol} /$ mol) stratum.

\section{HbA1c Level and risk of neuropathy}

Diabetic neuropathy, defined as the signs and symptoms of neuropathy wherein diabetes is the underlying cause, most frequently manifests as a distal, symmetric deficit [53]. For neuropathy, no trend in the pooled mean was seen when stratified according to HbA1c: $<6.0 \%$ (<42 mmol/ mol) (pooled mean of $2.06 \%$; 95\% CI: 0.02-6.76), 6-6.4\% (42-47 mmol/mol) (pooled mean 3.39\%; 95\% CI: $0.00-11.55)$ and $\geq 6.5 \%(\geq 48 \mathrm{mmol} / \mathrm{mol})$ (pooled mean $2.81 \%$; 95\% CI: 0.00-12.77). This may, however, be due to the paucity of studies available. 


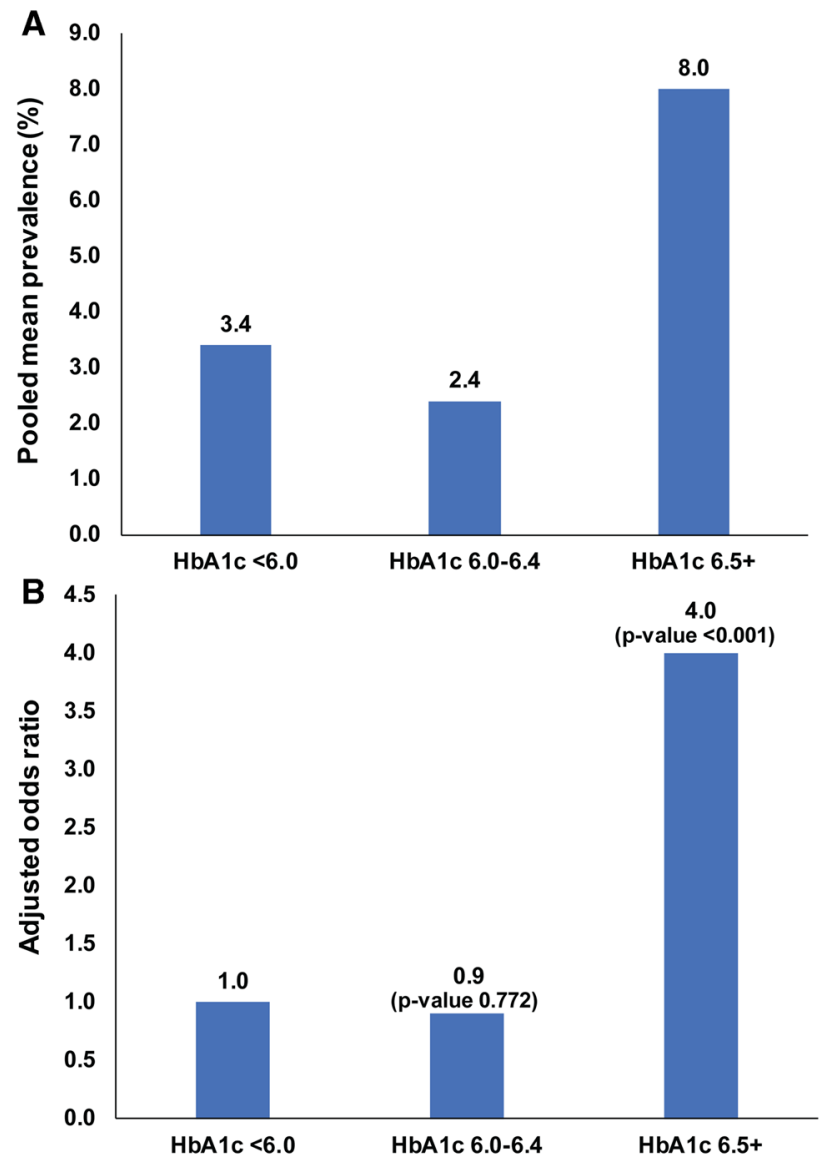

Fig. 4 Pooled mean prevalence and adjusted odds ratio of retinopathy according to HbA1c. a Prevalence of retinopathy (\%) stratified by $\mathrm{HbA} 1 \mathrm{c}$ levels of $<6.0 \%, 6.1-6.4 \%$ and $6.5 \%$ or greater, showing marked increase in retinopathy prevalence in the $6.5 \%$ or greater group. b Adjusted odds ratio for retinopathy prevalence (for age, sex and ethnicity) stratified by HbA1c levels of $<6.0 \%, 6.1-6.4 \%$ and $6.5 \%$ or greater, showing marked increase in the odds ratio in the $6.5 \%$ or greater group

\section{Subgroup Analysis}

As a higher prevalence of complications may be anticipated with increasing age, the meta-analysis data of studies reporting retinopathy were stratified by age using both two strata (age $\leq 55$ years and $>55$ years) and three strata (age $\leq 55$ years, age 55-59 years and $>60$ years) with levels of HbAlc (Table 5). As anticipated, the pooled means did tend to increase with age, though this trend did not differ substantially from the original analysis.

Certain ethnic populations are also known to develop diabetes complications more frequently, notably African-Americans [46]. A sensitivity analysis was therefore performed on the results of the meta-analysis for studies reporting

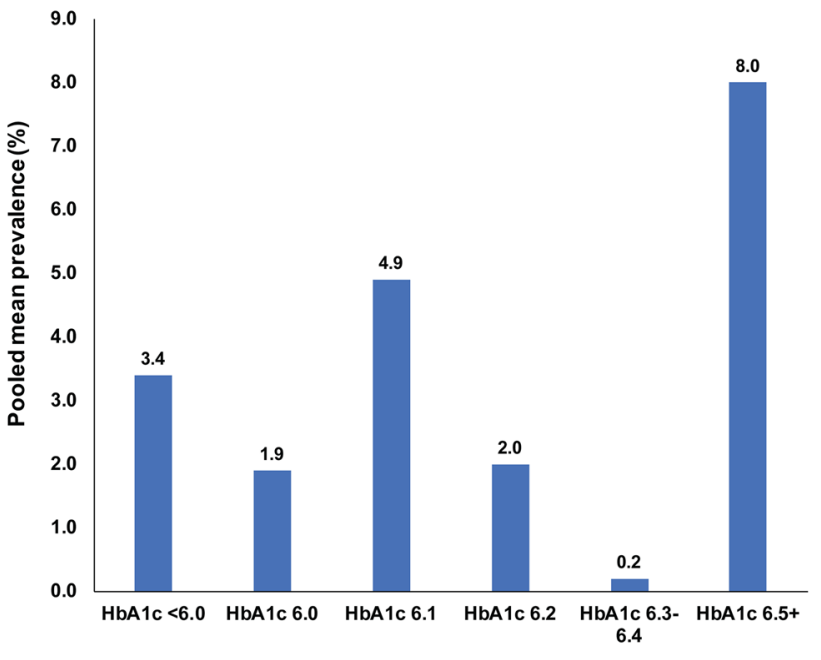

Fig. 5 Pooled mean prevalence of retinopathy stratified in $0.1 \%$ increments of HbA1c. The prevalence of retinopathy stratified in $0.1 \%$ increments showed no trend of increasing retinopathy for $\mathrm{HbA} 1 \mathrm{c}$ ranging from 6.0 to $6.4 \%$, but a marked increase in prevalence at $\mathrm{HbA} 1 \mathrm{c}$ of $6.5 \%$ and greater

retinopathy separately for African-Americans and non-Black populations (Table 6). The results showed the same upward trend for retinopathy with increasing levels of $\mathrm{HbAlc}$ in both the Black and non-Black populations, though the AfricanAmericans populations had a notably higher prevalence of retinopathy at every level of $\mathrm{HbAlc}$; the prevalence of retinopathy in non-African-Americans in those studies did not differ to the overall non-African American prevalence.

There were insufficient studies for both nephropathy and neuropathy to perform subgroup analyses.

\section{Meta-regression results}

Only retinopathy prevalence had a sufficient number of studies to warrant conduct of meta-regression analysis (Table 7).

The univariable analysis showed an association with prevalence for $\mathrm{HbA} 1 \mathrm{c}$ levels, age and race; these were therefore included in the multivariable model. Here, HbAlc stratification showed a marked and significant increase of retinopathy prevalence at $\geq 6.5 \%$ with an AOR of 4.0 (95\% CI: 1.9-8.5; $p<0.001)$ after controlling for the confounding effect of age and race. The model also showed that individuals $>55$ years of age had threefold higher odds for retinopathy than younger individuals (AOR: 3.3; 95\% CI: 1.8-6.0; $p<0.001$ ). African-Americans also had significantly higher odds for retinopathy prevalence than those of other race (AOR: 11.0; 95\% CI: 4.4-27.5; $p<0.001)$. This model explained $44.8 \%$ of the variation in retinopathy prevalence. 
Table 5 Results of meta-analyses of studies reporting retinopathy in patients with different $\mathrm{HbA1C}$ stratified by age

\begin{tabular}{|c|c|c|c|c|c|c|c|c|c|}
\hline & \multirow{2}{*}{$\begin{array}{l}\text { Studies } \\
\text { Total } N\end{array}$} & \multicolumn{2}{|l|}{ Sample } & \multicolumn{4}{|c|}{ Prevalence (\%) } & \multicolumn{2}{|c|}{ Heterogeneity measures } \\
\hline & & Tested & Number positive & Median & Range & Pooled mean & $95 \% \mathrm{CI}$ & $Q^{\mathrm{a}}(p$ value $)$ & $\mathrm{I}^{2 \mathrm{~b}}(\%, 95 \% \mathrm{CI})$ \\
\hline \multicolumn{10}{|l|}{ Retinopathy } \\
\hline \multicolumn{10}{|l|}{ Age $\leq 55$ years } \\
\hline $\mathrm{HbA} 1 \mathrm{C}<6.0$ & 4 & 9944 & 160 & 2.10 & $0.10-9.70$ & 2.38 & $0.63-5.16$ & $\begin{array}{l}118.4 \\
\quad(p<0.0001)\end{array}$ & $97.5(95.6-98.5)$ \\
\hline $\mathrm{HbA} 1 \mathrm{C}=6-6.4$ & 15 & 30,299 & 274 & 0.30 & $0.02-11.60$ & 1.17 & $0.52-2.07$ & $\begin{array}{l}506.9 \\
\quad(p<0.0001)\end{array}$ & $97.2(96.4-97.9)$ \\
\hline $\mathrm{HbA} 1 \mathrm{C} \geq 6.5$ & 11 & 12,771 & 574 & 5.00 & $0.40-19.10$ & 6.70 & $3.64-10.57$ & $\begin{array}{l}459.6 \\
\quad(p<0.0001)\end{array}$ & $97.8(97.1-98.4)$ \\
\hline \multicolumn{10}{|l|}{ Age $>55$ years } \\
\hline $\mathrm{HbA} 1 \mathrm{C}<6.0$ & 14 & 53,988 & 1,548 & 3.65 & $0.0-15.90$ & 3.73 & $1.75-6.37$ & $\begin{array}{l}2166.5 \\
\quad(p<0.0001)\end{array}$ & $99.4(99.3-99.5)$ \\
\hline $\mathrm{HbA} 1 \mathrm{C}=6-6.4$ & 17 & 61,623 & 1,415 & 3.85 & $0.62-14.80$ & 3.80 & $2.59-5.23$ & $\begin{array}{l}1001.6 \\
\quad(p<0.0001)\end{array}$ & $98.4(98.0-98.7)$ \\
\hline $\mathrm{HbA} 1 \mathrm{C} \geq 6.5$ & 13 & 43,130 & 2,352 & 6.44 & $1.57-48.30$ & 9.16 & $5.83-13.14$ & $\begin{array}{l}1715.9 \\
\quad(p<0.0001)\end{array}$ & $99.3(99.2-99.4)$ \\
\hline \multicolumn{10}{|l|}{ Age $<55$ years } \\
\hline $\mathrm{HbA} 1 \mathrm{C}<6.0$ & 4 & 9944 & 160 & 2.10 & $0.10-9.70$ & 2.38 & $0.63-5.16$ & $\begin{array}{l}118.4 \\
\quad(p<0.0001)\end{array}$ & $97.5(95.6-98.5)$ \\
\hline $\mathrm{HbA} 1 \mathrm{C}=6-6.4$ & 15 & 30,299 & 274 & 0.30 & $0.02-11.60$ & 1.17 & $0.52-2.07$ & $\begin{array}{l}506.9 \\
\quad(p<0.0001)\end{array}$ & $97.2(96.4-97.9)$ \\
\hline $\mathrm{HbA} 1 \mathrm{C} \geq 6.5$ & 11 & 12,771 & 574 & 5.00 & $0.40-19.10$ & 6.70 & $3.64-10.57$ & $\begin{array}{l}459.6 \\
\quad(p<0.0001)\end{array}$ & $97.8(97.1-98.4)$ \\
\hline \multicolumn{10}{|l|}{ Age $55-59$ years } \\
\hline $\mathrm{HbA} 1 \mathrm{C}<6.0$ & 5 & 43,074 & 523 & 1.45 & $0.60-6.0$ & 2.29 & $1.12-3.85$ & $\begin{array}{l}305.3 \\
\quad(p<0.0001)\end{array}$ & $98.7(98.1-99.1)$ \\
\hline $\mathrm{HbA} 1 \mathrm{C}=6-6.4$ & 11 & 57,555 & 1,209 & 3.85 & $0.99-10.00$ & 3.84 & $2.47-5.50$ & $\begin{array}{l}788.3 \\
\quad(p<0.0001)\end{array}$ & $98.7(98.4-99.0)$ \\
\hline $\mathrm{HbA} 1 \mathrm{C} \geq 6.5$ & 10 & 40,452 & 2,186 & 7.40 & $1.70-22.20$ & 8.97 & $5.24-13.57$ & $\begin{array}{l}1653.2 \\
\quad(p<0.0001)\end{array}$ & 99.5 (99.3-99.6) \\
\hline \multicolumn{10}{|l|}{ Age $\geq 60$ years } \\
\hline $\mathrm{HbA} 1 \mathrm{C}<6.0$ & 9 & 10,914 & 1,025 & 5.00 & $0.00-15.90$ & 4.69 & $1.58-9.26$ & $\begin{array}{l}637.5 \\
\quad(p<0.0001)\end{array}$ & 98.7 (98.4-99.0) \\
\hline $\mathrm{HbA} 1 \mathrm{C}=6-6.4$ & 6 & 4,068 & 206 & 3.06 & $0.62-14.80$ & 3.72 & $1.22-7.44$ & $\begin{array}{l}119.1 \\
\quad(p<0.0001)\end{array}$ & $95.8(93.1-97.5)$ \\
\hline $\mathrm{HbA} 1 \mathrm{C} \geq 6.5$ & 3 & 2678 & 166 & 6.44 & $1.57-48.30$ & 10.84 & $2.65-23.19$ & $53.7(p<0.0001)$ & $96.3(92.1-98.2)$ \\
\hline
\end{tabular}

${ }^{a} Q$ : the Cochran's $Q$ statistic is a measure assessing the existence of heterogeneity in effect size (here, prevalence) across studies

${ }^{\mathrm{b}} I^{2}$ : a measure assessing the magnitude of between-study variation that is due to differences in effect size (here, prevalence) across studies rather than chance

\section{Discussion}

The meta-analysis relating stratified HbA1c to the prevalence of retinopathy, nephropathy and neuropathy showed clearly that for moderate retinopathy, the recent data are in accord with a HbAlc diagnostic cutoff of $6.5 \%(48 \mathrm{mmol} /$ mol and above) for T2DM, with the inflection point for the increase in diabetic retinopathy prevalence being at $6.5 \%$ ( $48 \mathrm{mmol} / \mathrm{mol}$ ), as also shown by the stratified analysis using the $J$-shaped curve. Pooled mean retinopathy prevalence by $0.1 \% \mathrm{HbA} 1 \mathrm{c}$ changes showed no obvious signal of a rising retinopathy prevalence for $\mathrm{HbA} 1 \mathrm{c} 6.0$ to $6.4 \%$, with the inflection point being at $6.5 \%$ or greater. This being said, there were too few studies assessing retinopathy prevalence at $\mathrm{HbA} 1 \mathrm{c}$ increments of $6.3 \%$ and $6.4 \%$ for evidence to be conclusive. The latter analysis also showed considerable retinopathy prevalence at below $6.0 \%(42 \mathrm{mmol} / \mathrm{mol})$ HbA1c. It should be also emphasized that the stratification of $\mathrm{HbAlc}$ and retinopathy was based on the detection of moderate retinopathy and it is unknown whether the diagnostic cutpoint for T2DM may be altered by prevalence studies on minimal diabetic retinopathy. These results differ from that reported in a previous meta-analysis that concluded that HbAlc thresholds could not be identified from the studies 
Table 6 Sensitivity analysis showing results of meta-analyses of studies reporting retinopathy in patients with different HbA1C excluding African-American patients

\begin{tabular}{lllllll} 
Studies & Sample & & \multicolumn{2}{l}{ Prevalence $(\%)$} & & Heterogeneity measures \\
Total $N$ & Tested $\begin{array}{l}\text { Number posi- } \\
\text { tive }\end{array}$ & Median Range & Pooled mean 95\% CI & & $Q^{\mathrm{a}}(p$ value $) \quad I^{2 \mathrm{~b}}(\%, 95 \% \mathrm{CI})$
\end{tabular}

\begin{tabular}{|c|c|c|c|c|c|c|c|c|c|}
\hline \multicolumn{10}{|l|}{ Retinopathy } \\
\hline \multicolumn{10}{|c|}{ Non-African-American } \\
\hline $\mathrm{HbA} 1 \mathrm{C}<6.0$ & 16 & 63,483 & 1660 & 1.88 & $0.00-15.90$ & 2.79 & $1.34-4.72$ & $\begin{array}{l}2232.1 \\
\quad(p<0.0001)\end{array}$ & $99.3(99.2-99.4)$ \\
\hline $\mathrm{HbA} 1 \mathrm{C}=6-6.4$ & 29 & 90,744 & 1548 & 1.07 & $0.02-10.00$ & 1.87 & $1.22-2.64$ & $\begin{array}{l}1599.7 \\
\quad(p<0.0001)\end{array}$ & $98.2(97.9-98.5)$ \\
\hline $\mathrm{HbA} 1 \mathrm{C} \geq 6.5$ & 21 & 54,997 & 2748 & 5.14 & $0.40-22.20$ & 6.67 & $4.59-9.10$ & $\begin{array}{l}1956.6 \\
\quad(p<0.0001)\end{array}$ & $99.0(98.8-99.1)$ \\
\hline \multicolumn{10}{|l|}{ African-American } \\
\hline $\mathrm{HbA} 1 \mathrm{C}<6.0$ & 2 & 449 & 48 & 12.05 & $9.70-14.40$ & 11.14 & $6.98-16.09$ & $1.8(p=0.1793)$ & $44.6(-)$ \\
\hline $\mathrm{HbA} 1 \mathrm{C}=6-6.4$ & 3 & 1178 & 141 & 11.6 & $10.90-14.80$ & 11.89 & $10.09-13.81$ & $1.7(p=0.4192)$ & $0.0(0.0-88.0)$ \\
\hline $\mathrm{HbA} 1 \mathrm{C} \geq 6.5$ & 3 & 904 & 178 & 19.10 & $14.80-48.30$ & 23.94 & $12.08-38.19$ & $\begin{array}{l}12.6 \\
\quad(p=0.0018)\end{array}$ & $84.1(52.4-94.7)$ \\
\hline
\end{tabular}

${ }^{a} Q$ : the Cochran's $Q$ statistic is a measure assessing the existence of heterogeneity in effect size (here, prevalence) across studies

${ }^{\mathrm{b}} I^{2}$ : a measure assessing the magnitude of between-study variation that is due to differences in effect size (here, prevalence) across studies rather than chance

on microvascular complications, though the threshold of $\mathrm{HbA} 1 \mathrm{c}$ of $6.5 \%$ was strong for severe retinopathy [13].

The heterogeneity in the retinopathy data was controlled for in the meta-regression and showed, in both the univariate and multivariate analyses, the increased odds ratio of 3.2 and 4.05 , respectively, with an $\mathrm{HbA} 1 \mathrm{c}$ of $6.5 \%$ or greater; however, as noted the stratified HbA1c data revealed a $J$-shaped curve showing accountable retinopathy prevalence at below $6.0 \%$. The meta-regression also revealed the increase in retinopathy prevalence with those aged over 55 years, with an OR of 3.23 and a striking increase in retinopathy prevalence for African-Americans with an OR of 10.73 on multivariate analysis. While this is in accord with the previous data [3, 9-11], retinopathy clearly occurs earlier than the cutoff of $6.5 \%$. The magnitude of the association of retinopathy with race found here may not be representative as only 8 studies were available among African-Americans, though it raises the question whether a different diagnostic cutoff for T2DM for African-Americans aged greater than 55 years may be appropriate, as they would appear to be the group at greatest risk [54]. It should also be emphasized that the stratification of $\mathrm{HbAlc}$ and retinopathy was based on the detection of moderate retinopathy and it is unknown whether the diagnostic cutpoint for T2DM may be altered by prevalence studies on minimal diabetic retinopathy. Thus, the T2DM diagnostic cutpoint for HbA1c may not be a universal "one size fits all," but may need to be stratified according to age and race.

The main limitations of the 22 studies of retinopathy included in the meta-analysis were that retinal photography was not standardized and that the degree of retinopathy was often reported as moderate or poorly specified [27, 38]. As different studies have measured the complications in different ways, this may have affected the outcome and we may therefore have underestimated the prevalence of the diabetic complications. There were few studies focusing specifically on the onset of minimal diabetes retinopathy. In addition, minimal retinopathy may be difficult to differentiate between diabetes and non-diabetes-related retinopathy and therefore only moderate diabetes changes were identified in all studies analyzed. This could suggest that with a standardized procedure specifically identifying minimal diabetic retinopathy, that the inflection point for the onset of retinopathy would be a HbA1c lower than $6.5 \%$ ( $48 \mathrm{mmol} / \mathrm{mol})$, but this is clearly speculative as there is insufficient evidence to support this at present.

Four studies were evaluated which considered the onset of nephropathy, the data showing that the HbA1c cutoff of $6.5 \%$ (48 mmol $/ \mathrm{mol})$ was appropriate with a significant increase in the urine albumin/creatinine ratio. Again, it is evident that there were significant numbers of subjects with albuminuria in the range of "prediabetes" between 6.0-6.4\% (42-47 mmol $/ \mathrm{mol})$; however, the main limitations were the small number of studies, heterogeneity of the population and lack of division of the $\mathrm{HbA} 1 \mathrm{c}$ level into $0.1 \%$ ranges that prevented a more stringent determination. In addition, all of the studies were cross sectional with a need for longitudinal studies to be performed.

There were only three studies with sufficient data that could be evaluated for the onset of neuropathy, and these 


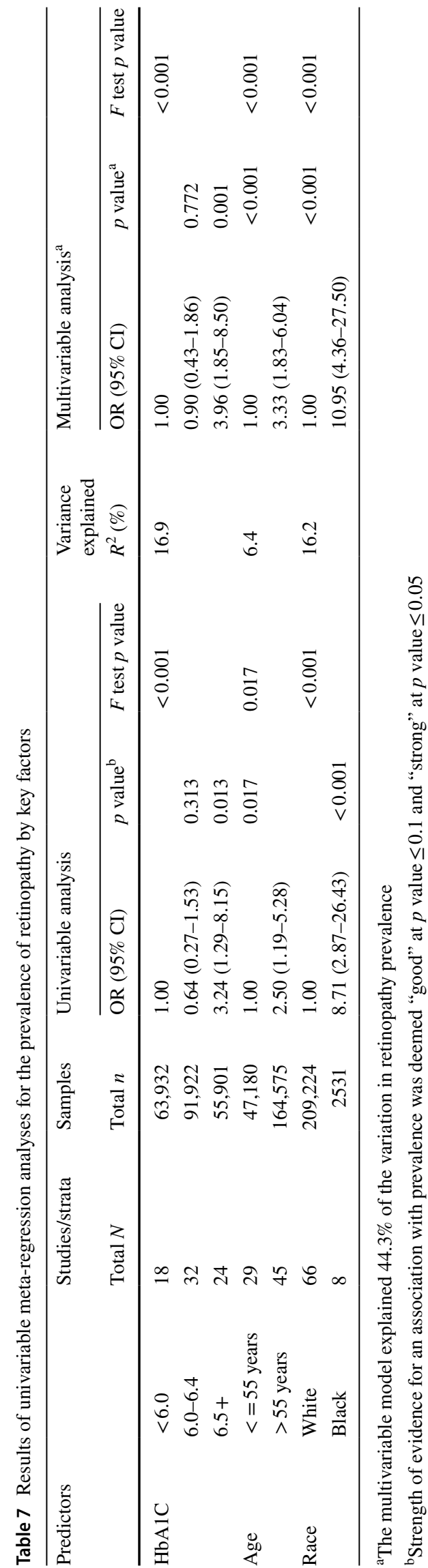

were inconclusive with no inflection point seen for the $\mathrm{HbA} 1 \mathrm{c}$ cutoff, with a prevalence of neuropathy at an $\mathrm{HbA} 1 \mathrm{c}$ of $6.0-6.4(42-46 \mathrm{mmol} / \mathrm{mol})$ being the same as that of $6.5 \%$ (48 $\mathrm{mmol} / \mathrm{mol}$ ) and above. The main limitations here include the limited amount of data in too few studies, heterogeneity of the population and poor division of the $\mathrm{HbA} 1 \mathrm{c}$ range into $0.1 \%$ ranges; however, given the limited data, it is unlikely that division of $\mathrm{HbA} 1 \mathrm{c}$ into $0.1 \%$ ranges would have allowed a more stringent determination.

\section{Conclusions}

In conclusion, based on the strongest data of moderate retinopathy, this systematic review and meta-analysis is in accord that the HbA1c diagnostic cutpoint of $6.5 \%(48 \mathrm{mmol} /$ $\mathrm{mol}$ ) is highly specific for diagnosing T2DM, though the increased prevalence of retinopathy in those aged 55 years or greater and in African-Americans may suggest a lower threshold is appropriate for those groups. However, this analysis highlights that diabetic microvascular complications commonly occur at lower $\mathrm{HbA} 1 \mathrm{c}$ values, and the sensitivity of diagnosing T2DM may improve with a lower diagnostic cutpoint. There is a need for studies that standardize the definition of minimal diabetic retinopathy with more sensitive measures of nephropathy and neuropathy to determine if a lower threshold is appropriate.

Acknowledgements The authors acknowledge the services provided by the Biostatistics, Epidemiology, and Biomathematics Research Core at the Weill Cornell Medicine-Qatar. SLA is the guarantor of this work and, as such, had full access to all the data in the study and takes responsibility for the integrity of the data and the accuracy of the data analysis.

Author contributions AEB and SLA performed the systematic analysis, interpreted the data and wrote the manuscript. WGJ, EE, EK and KGMMA conceived of the study and contributed to the writing of the manuscript. HC and LJAR analyzed and interpreted the data and contributed to the writing of the manuscript. LO performed the search and assisted with writing the manuscript. All authors reviewed and approved the final version of the manuscript.

Funding Open Access funding provided by the Qatar National Library.

Availability of data and materials All the data for this study will be made available upon reasonable request to the corresponding author.

\section{Compliance with ethical standards}

Conflict of interest No authors have any conflict of interest or competing interests to declare.

Consent to participate Not applicable.

Consent for publication All authors gave their consent for publication. 
Ethics approval Not applicable.

Informed consent Since the studies included in this systematic review and meta-analysis are already published work and therefore in the public domain with no individual identifying information, no informed consent was required to undertake this study.

Human and Animal Rights No animals were used in the performance of this systematic review and meta-analysis.

Open Access This article is licensed under a Creative Commons Attribution 4.0 International License, which permits use, sharing, adaptation, distribution and reproduction in any medium or format, as long as you give appropriate credit to the original author(s) and the source, provide a link to the Creative Commons licence, and indicate if changes were made. The images or other third party material in this article are included in the article's Creative Commons licence, unless indicated otherwise in a credit line to the material. If material is not included in the article's Creative Commons licence and your intended use is not permitted by statutory regulation or exceeds the permitted use, you will need to obtain permission directly from the copyright holder. To view a copy of this licence, visit http://creativecommons.org/licenses/by/4.0/.

\section{References}

1. DF Diabetes Atlas (2017); 8th:ttp://www.diabetesatlas.org

2. Targets G (2019) Standards of medical care in diabetes-2019. Diabetes Care 42(Suppl 1):S61-s70

3. Report of the expert committee on the diagnosis and classification of diabetes mellitus (1997) Diabetes Care, vol 20(7), pp1183-1197

4. Genuth S, Alberti KG, Bennett P et al (2003) Follow-up report on the diagnosis of diabetes mellitus. Diabetes Care 26(11):3160-3167

5. Zhang X, Gregg EW, Williamson DF et al (2010) A1C level and future risk of diabetes: a systematic review. Diabetes Care 33(7):1665-1673

6. Selvin E, Ning Y, Steffes MW et al (2011) Glycated hemoglobin and the risk of kidney disease and retinopathy in adults with and without diabetes. Diabetes 60(1):298-305

7. Ackermann RT, Cheng YJ, Williamson DF, Gregg EW (2011) Identifying adults at high risk for diabetes and cardiovascular disease using hemoglobin A1c national health and nutrition examination survey 2005-2006. Am J Prev Med 40(1):11-17

8. Gillett MJ (2009) International expert committee report on the role of the A1c assay in the diagnosis of diabetes: diabetes care 2009; 32(7): 1327-1334. Clin Biochem Rev 30(4):197-200

9. Colagiuri S, Lee CM, Wong TY, Balkau B, Shaw JE, Borch-Johnsen K (2011) Glycemic thresholds for diabetes-specific retinopathy: implications for diagnostic criteria for diabetes. Diabetes Care 34(1):145-150

10. McCance DR, Hanson RL, Charles MA et al (1994) Comparison of tests for glycated haemoglobin and fasting and two hour plasma glucose concentrations as diagnostic methods for diabetes. BMJ (Clin Res Ed) 308(6940):1323-1328

11. Engelgau MM, Thompson TJ, Herman WH et al (1997) Comparison of fasting and 2-hour glucose and HbA1c levels for diagnosing diabetes. Diagnostic criteria and performance revisited. Diabetes Care 20(5):785-791

12. Cowie CC, Rust KF, Byrd-Holt DD et al (2010) Prevalence of diabetes and high risk for diabetes using A1C criteria in the US population in 1988-2006. Diabetes Care 33(3):562-568
13. Kowall B, Rathmann W (2013) HbA1c for diagnosis of type 2 diabetes. Is there an optimal cut point to assess high risk of diabetes complications, and how well does the $6.5 \%$ cutoff perform? Diabetes, Metab Syndr Obes Targets Ther 6:477-491

14. Higgins JP, Green S (2011) Cochrane handbook for systematic reviews of interventions. Wiley, New Jersey

15. Moher D, Liberati A, Tetzlaff J, Altman DG, Group P (2009) Preferred reporting items for systematic reviews and meta-analyses: the PRISMA statement. J Clin Epidemiol 62(10):1006-1012

16. McGowan J, Sampson M, Salzwedel DM, Cogo E, Foerster V, Lefebvre C (2016) PRESS peer review of electronic search strategies: 2015 guideline statement. J Clin Epidemiol 75:40-46

17. Higgins JPT, Green S (2008) Cochrane Collaboration Cochrane handbook for systematic reviews of interventions. Wiley-Blackwell, NJ

18. Freeman MF, Tukey JW (1950) Transformations related to the angular and the square root. Ann Math Stat 21:607-611

19. Miller JJ (1978) The inverse of the freeman-Tukey double arcsine transformation. Am Stat 32(4):138-138

20. Barendregt JJ, Doi SA, Lee YY, Norman RE, Vos T (2013) Meta-analysis of prevalence. J Epidemiol Commun Health 67(11):974-978

21. DerSimonian R, Laird N (1986) Meta-analysis in clinical trials. Control Clin Trials 7(3):177-188

22. Borenstein M (2009) Introduction to meta-analysis. John Wiley $\&$ Sons, Chichester

23. Higgins JP, Thompson SG (2002) Quantifying heterogeneity in a meta-analysis. Stat Med 21(11):1539-1558

24. R core team (2017) R: a language and environment for statistical computing. Vienna, Austria: R Foundation for Statistical Computing

25. StataCorp (2015) Stata Statistical Software: Release 14. College Station, TX: StataCorp LP. 2015

26. Harbord RM, Higgins JPT (2008) Meta-regression in Stata. Stata J 8(4):493-519

27. Ito C, Maeda R, Ishida S, Harada H, Inoue N, Sasaki H (2000) Importance of OGTT for diagnosing diabetes mellitus based on prevalence and incidence of retinopathy. Diabetes Res Clin Pract 49(2-3):181-186

28. Tapp RJ, Zimmet PZ, Harper CA et al (2006) Diagnostic thresholds for diabetes: the association of retinopathy and albuminuria with glycaemia. Diabetes Res Clin Pract 73(3):315-321

29. Samadi Aidenloo N, Mehdizadeh A, Valizadeh N, Abbaszadeh M, Qarequran S, Khalkhali H (2016) Optimal glycemic and hemoglobin A1c thresholds for diagnosing diabetes based on prevalence of retinopathy in an Iranian population. Irani Red Crescent Medl J 18(8):e31254

30. Almdal TP, Handlos LN, Valerius M et al (2014) Glycaemic threshold for diabetes-specific retinopathy among individuals from Saudi Arabia, Algeria and Portugal. Diabetes Res Clin Pract 103(3):e44-46

31. Bertelsen G, Peto T, Lindekleiv H et al (2014) Sex differences in risk factors for retinopathy in non-diabetic men and women: the tromso eye study. Acta Ophthalmol 92(4):316-322

32. Bower JK, Brancati FL, Selvin E (2013) No ethnic differences in the association of glycated hemoglobin with retinopathy: the national health and nutrition examination survey 2005-2008. Diabetes Care 36(3):569-573

33. Cheng YJ, Gregg EW, Geiss LS et al (2009) Association of A1c and fasting plasma glucose levels with diabetic retinopathy prevalence in the US population: implications for diabetes diagnostic thresholds. Diabetes Care 32(11):2027-2032

34. Cho NH, Kim TH, Woo SJ et al (2013) Optimal HbA1c cutoff for detecting diabetic retinopathy. Acta Diabetol 50(6):837-842 
35. Fukushima S, Nakagami T, Suto C, Hirose A, Uchigata Y (2013) Prevalence of retinopathy and its risk factors in a Japanese population. J Diabetes Invest 4(4):349-354

36. Park YM, Ko SH, Lee JM et al (2014) Glycaemic and haemoglobin A1c thresholds for detecting diabetic retinopathy: the fifth Korea national health and nutrition examination survey (2011). Diabetes Res Clin Pract 104(3):435-442

37. Lamparter J, Raum P, Pfeiffer N et al (2014) Prevalence and associations of diabetic retinopathy in a large cohort of prediabetic subjects: the Gutenberg health study. J Diabetes Complicat 28(4):482-487

38. Metcalf PA, Kyle C, Kenealy T, Jackson RT (2017) HbA1c in relation to incident diabetes and diabetes-related complications in non-diabetic adults at baseline. J Diabetes Complicat 31(5):814-823

39. Nakagami T, Takahashi K, Suto $C$ et al (2017) Diabetes diagnostic thresholds of the glycated hemoglobin A1c and fasting plasma glucose levels considering the 5-year incidence of retinopathy. Diabetes Res Clin Pract 124:20-29

40. Okosun IS, Turbow S, McJenkin K, Monique Davis-Smith Y, Seale JP (2016) Diagnostic performance of glycated hemoglobin for diabetic retinopathy in non-diabetic older overweight/obese African-Americans. Diabetes Res Clin Pract 120:124-131

41. Pang C, Jia L, Jiang S et al (2012) Determination of diabetic retinopathy prevalence and associated risk factors in Chinese diabetic and pre-diabetic subjects: Shanghai diabetic complications study. Diabetes/Metabol Res Rev 28(3):276-283

42. Sabanayagam C, Khoo EY, Lye WK et al (2015) Diagnosis of diabetes mellitus using HbA1c in Asians: relationship between $\mathrm{HbA1c}$ and retinopathy in a multiethnic Asian population. J Clin Endocrinol Metabol 100(2):689-696

43. Sabanayagam C, Liew G, Tai ES et al (2009) Relationship between glycated haemoglobin and microvascular complications: is there a natural cut-off point for the diagnosis of diabetes? Diabetologia 52(7):1279-1289

44. Tsugawa Y, Takahashi O, Meigs JB et al (2012) New diabetes diagnostic threshold of hemoglobin $\mathrm{A}(1 \mathrm{c})$ and the 3-year incidence of retinopathy. Diabetes 61(12):3280-3284
45. Massin P, Lange $\mathrm{C}$, Tichet $\mathrm{J}$ et al (2011) Hemoglobin A1c and fasting plasma glucose levels as predictors of retinopathy at 10 years: the French DESIR study. Arch Ophthalmol 129(2):188-195

46. Tsugawa Y, Mukamal KJ, Davis RB, Taylor WC, Wee CC (2012) Should the hemoglobin A1c diagnostic cutoff differ between blacks and whites? A cross-sectional study. Ann Intern Med 157(3):153-159

47. Toulis KA, Jiang CQ, Hemming K et al (2018) Glycated hemoglobin, albuminuria and surrogate markers of macrovascular disease in adults without diabetes: the Guangzhou Biobank cohort study, cardiovascular disease subcohort. Can J Diabetes 42(3):245-250.e241

48. Xing FY, Neeland IJ, Gore MO et al (2014) Association of prediabetes by fasting glucose and/or haemoglobin A1c levels with subclinical atherosclerosis and impaired renal function: observations from the Dallas Heart Study. Diabetes Vasc Dis Res 11(1):11-18

49. Tapp RJ, Shaw JE, de Courten MP, Dunstan DW, Welborn TA, Zimmet PZ (2003) Foot complications in Type 2 diabetes: an Australian population-based study. Diabetic Med 20(2):105-113

50. Kurisu SO KI, Sasaki H, Tanaka H, Yamaneki M, Nakanishi I, Furuta H, et al. (2016) Polyneuropathy or neuropathic pain did not increase at prediabetic stage in Japanese population. J Diabetes Invest

51. Solomon SD, Chew E, Duh EJ et al (2017) Diabetic retinopathy: a position statement by the American diabetes association. Diabetes Care 40(3):412-418

52. Stevens PE, Levin A (2013) Kidney disease: improving global outcomes chronic kidney disease guideline development Work group M. Evaluation and management of chronic kidney disease: synopsis of the kidney disease: improving global outcomesclinical practice guideline. Ann Intern Med 158(11):825-830

53. Bansal V, Kalita J, Misra UK (2006) Diabetic neuropathy. Postgrad Med J 82(964):95-100

54. Chatterjee R, Maruthur NM, Edelman D (2015) Novel risk factors for type 2 diabetes in African-Americans. Curr DiabRep 15(12):103

Publisher's Note Springer Nature remains neutral with regard to jurisdictional claims in published maps and institutional affiliations.

\section{Affiliations}

\section{Alexandra E. Butler ${ }^{1}\left(\mathbb{D} \cdot\right.$ Emma English $^{2}$ - Eric S. Kilpatrick ${ }^{3}$. Linda Östlundh ${ }^{4} \cdot$ Hiam S. Chemaitelly $^{5}$. Laith J. Abu-Raddad ${ }^{5} \cdot$ K. George M. M. Alberti ${ }^{6}$. Stephen L. Atkin ${ }^{7}$ · W. Garry John ${ }^{2,8}$}

Alexandra E. Butler

aeb91011@gmail.com; abutler@hbku.edu.qa

1 Diabetes Research Center (DRC), Qatar Biomedical Research Institute (QBRI), Hamad Bin Khalifa University (HBKU), Qatar Foundation (QF), PO Box 34110, Doha, Qatar

2 University East Anglia, Norwich, UK

3 Sidra Medicine, Doha, Qatar
4 College of Medicine and Health Sciences, United Arab Emirates University, Al Ain, UAE

5 Infectious Disease Epidemiology Group, Weill Cornell Medicine-Qatar, Cornell University, Qatar Foundation-Education City, Doha, Qatar

6 Imperial College, London, UK

7 Royal College of Surgeons Ireland, Busaiteen, Bahrain

8 Norfolk and Norwich University Hospital, Norwich, UK 